\title{
Schrift und sakraler Außenraum
}

\section{Tempelfassaden und monumentale Friesinschriften im Mittelalter}

Das ungewöhnlichste schrifttragende Bauwerk des frühen Mittelalters steht in Umbrien unweit der Via Flaminia, bei den seit der Antike wegen ihrer landschaftlichen Idylle berühmten Quellen des Clitumnus (Clitunno), eines Nebenflusses des Topino (Abb.1). Im Spätmittelalter diente das Kirchengebäude als Pfarrkirche San Salvatore für den umliegenden Ort Pissignano. Es hat die Gestalt eines römischen Podiumstempels mit vier Säulen zwischen den Anten, mit ehemals zwei seitlichen, ebenfalls giebelbekrönten Vorhallen, zu denen Treppen hinaufführten. ${ }^{1}$ In erstaunlicher Kontinuität gilt dieses Gebäude seit dem 15. Jahrhundert bei Architekten und Archäologen als der durch antike Autoren überlieferte Tempel des Jupiter Clitumnus; ${ }^{2}$ dies prägt auch die in der Kunstgeschichte übliche Benennung als „Tempietto del Clitunno“. Die durch den Baubefund nahegelegte Deutung, dass es sich um ein originär als christliche Kirche errichtetes Gebäude handelt, ist in der jüngeren Forschung nicht mehr begründet angezweifelt worden, und auch für die Datierung hat sich eine Zeitstellung im 8. Jahrhundert durchgesetzt. Das von Ranken umspielte große Kreuz im Tympanon belegt dies ebenso wie Gestaltung und Ausmalung der Apsis im Inneren.

Der Fries des Gebälks der nach Westen gerichteten Fassade (Abb. 2) trägt in $14 \mathrm{~cm}$ hohen Kapitalisbuchstaben die Inschrift + SCS DEVS ANGELORUM QVI FECIT RESVRECTIONEM (sanctus deus angelorum qui fecit resurrectionem - Heilig ist der Gott der Engel, der die Auferstehung bewirkt). Baufragmente sowie Architekten und Antiquare des 16. und 17. Jahrhunderts überliefern in Text und Bild zwei weitere, etwas kleinere Inschriften auf den Friesen der seitlichen, nach Norden und Süden gerichteten Vorhallen, von denen noch Fragmente erhalten sind (Abb.3): SCS DEVS PROFETA[...]EM (sanctus deus propheta[rum qui fecit redemption]em - Heilig ist der Gott der Propheten, der die Erlösung bewirkt) und [...]SIONEM ([sanctus deus apostolorum qui fecit remis]sionem - Heilig ist der Gott der Apostel, der die Vergebung [der Sünden] bewirkt). ${ }^{3}$ Auch wenn das Gebäude selbst keine Umnutzung des

1 Emerick 1992; Jäggi 1998, 149-194, 223-235.

2 Schoder 1979.

3 Corpus Inscriptionum Latinarum XI.2, Nr. 4964; Binazzi 1989, 126-129 Nr. 81; Emerick 1992, 86, mit Verweis auf überlieferte Lesungen von ca. 1525, 1666, 1672 u. 1699. - Im Kontext des Apostolischen

Dieser Beitrag ist im Heidelberger Sonderforschungsbereich 933 „Materiale Textkulturen. Materialität und Präsenz des Geschriebenen in non-typographischen Gesellschaften“ entstanden (Teilprojekt A05 „Schrift und Schriftzeichen am und im mittelalterlichen Kunstwerk“). Der SFB 933 wird durch die Deutsche Forschungsgemeinschaft finanziert.

๑ Open Access. (C) 2019 Matthias Untermann, publiziert von De Gruyter. (c) BY-NC-ND Dieses Werk ist lizenziert unter der Creative Commons Attribution-NonCommercial-NoDerivatives 4.0 Lizenz.

https://doi.org/10.1515/9783110629156-011 
überlieferten, antiken Quellgott-Heiligtums darstellt, so beanspruchte es in seinem Erscheinungsbild für jeden erkennbar in antiken Formen die Herrschaft des christlichen Gottes über die himmlischen Heerscharen, die Propheten des Alten und die Apostel des Neuen Testaments sowie die Grundversprechen der christlichen Religion, Auferstehung der Toten, Erlösung vom Bösen und Vergebung der Sünden.

Die in den drei Inschriften vorgetragene religiöse Botschaft auf dem Sakralgebäude entspricht nicht den damaligen Seherwartungen für eine christliche Kirche, aber auch nicht für eine antik-römische Tempelfassade. In der Fassade öffnet sich nur eine Tür zum Untergeschoss, zwei Treppen führen von Norden und Süden zu den Vorhallen des Hauptgeschosses hinauf. Der heutige architektonische Kontext - die Rückseite der an einer Hangkante erbauten Kirche ist zur Landstraße gerichtet, die talseitige Front zu einem Bauernhof - fordert Überlegungen zur bauzeitlichen Konzeption.

Die Inschriften am „Tempietto del Clitunno“ sind die ältesten derzeit bekannten monumentalen Fassadeninschriften im Bereich des westlichen Christentums. Die kostbare Bauskulptur verbindet dieses Gebäude eng mit der Werkstatt, die in der nahen Bischofsstadt Spoleto, Residenz eines langobardischen Herzogs, die Abteikirche St. Concordius und Sentia (heute: San Salvatore) mit hochrangiger Bauskulptur ausgestattet hat. Deren Fassade trug allerdings keine Inschrift. Die Datierung beider Bauten ist unsicher; gute Argumente sprechen für eine Entstehung zwischen ca. 700 und $770 .{ }^{4}$

\section{Fassadeninschriften an mittelalterlichen Kirchen}

Kristina Krüger hat 2014 am Fallbeispiel der Abteikirche Corvey die Funktion einer aufwändig gestalteten, antikennahen Fassadeninschrift des frühen Mittelalters untersucht, für eine Region, die bis dahin keine öffentliche Schriftlichkeit kannte und in der keine Lateinkenntnisse vorhanden waren. Dies ist zweifellos ein Extremfall restringierter Präsenz.

In großen Teilen des ehemaligen römischen Reichs gibt es keinen grundsätzlichen Zweifel daran, dass relevante Teile der Bevölkerung auch nach dem Ende des römischen Reichs lesen konnten und Latein zumindest in den Grundzügen verstanden. Hier finden sich vom 8. bis 15. Jahrhundert eine gewisse Zahl monumentaler Fassadeninschriften römischer Tradition, von denen die des „Tempietto del Clitunno“ die derzeit älteste bekannte ist. Vor dem Hintergrund, dass in römisch-antiker Zeit praktisch alle Tempel und öffentlichen Großbauten monumentale Inschriften aufwie-

Glaubensbekenntnisses wäre statt redemptionem [a malo] eher zu erwarten ... qui fecit [sanctorum] communionem.

4 Zur Datierungsdebatte ausführlich Jäggi 1998. 


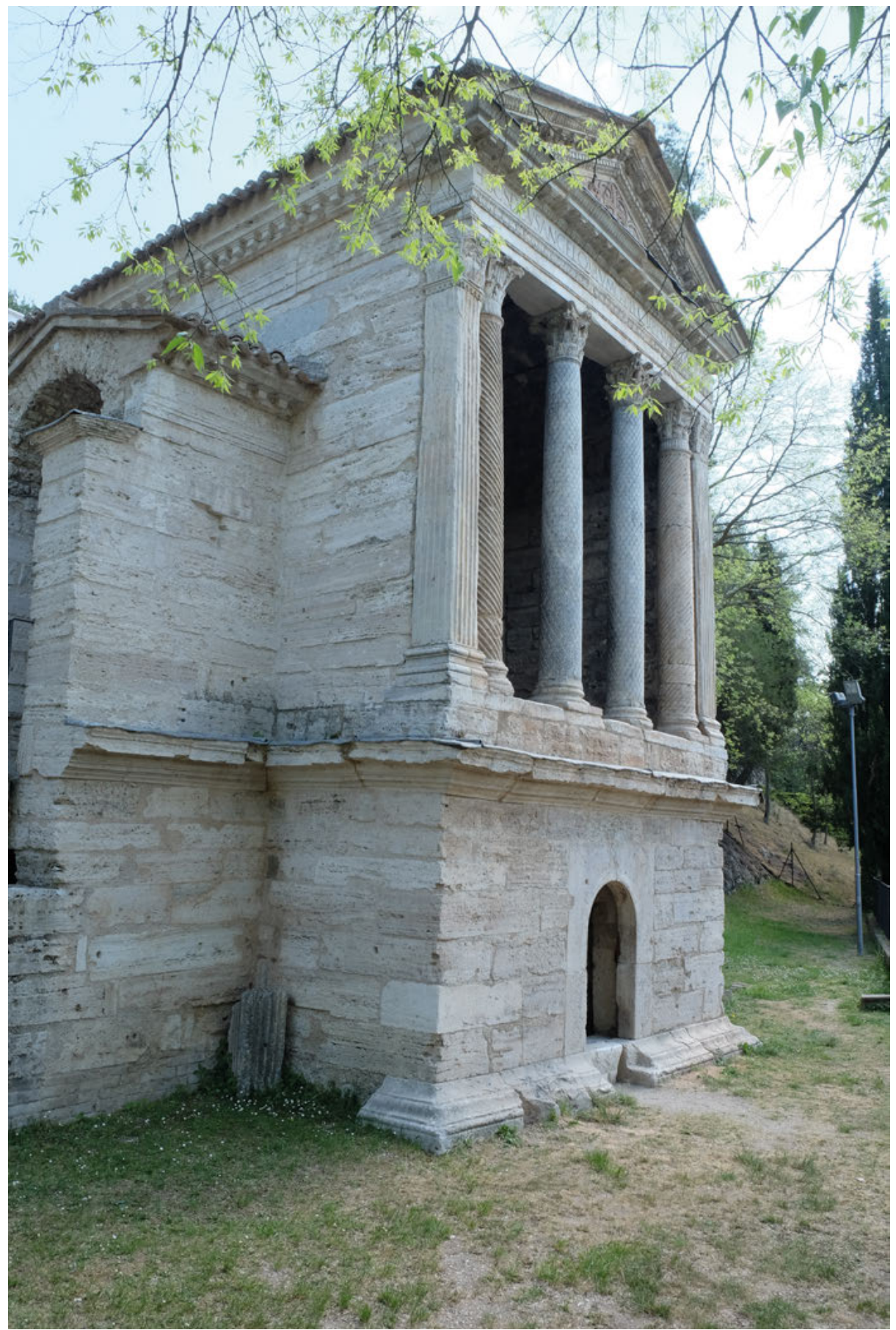

Abb.1: San Salvatore di Pissignano (Tempietto del Clitunno), von Nordwesten. 


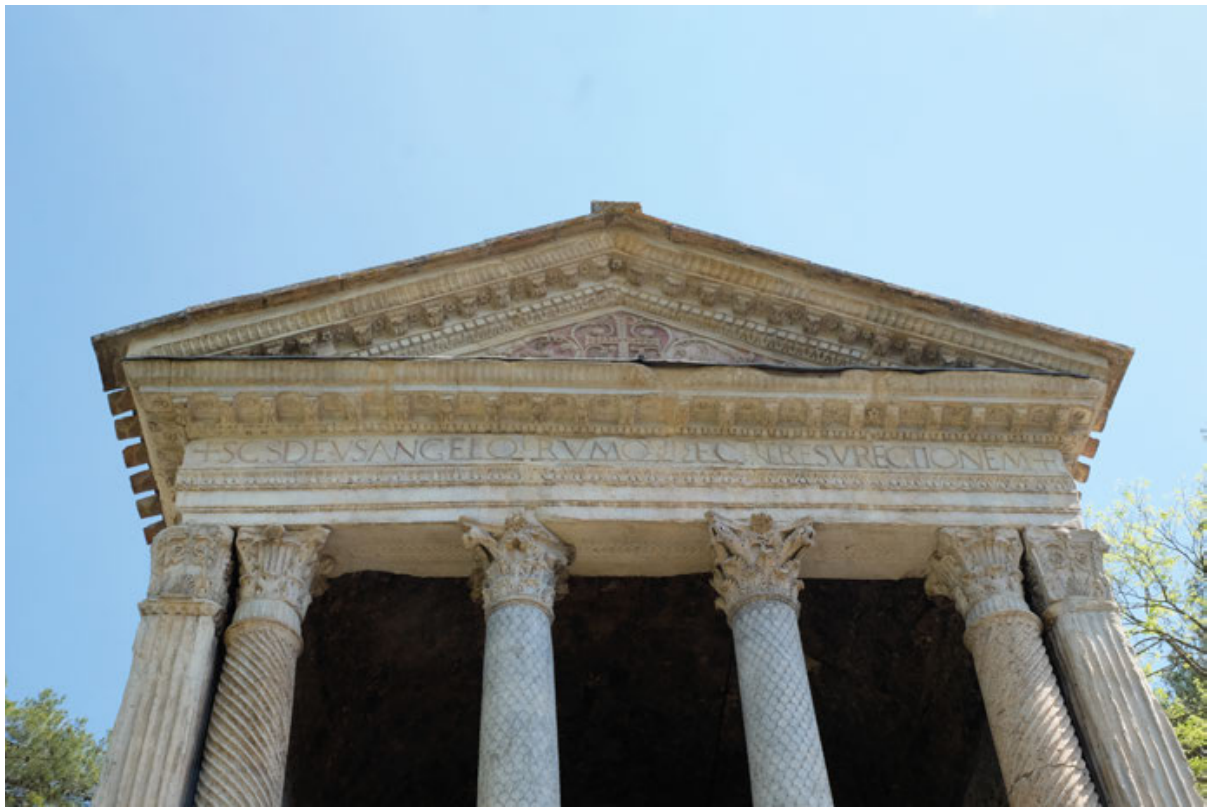

Abb. 2: San Salvatore di Pissignano (Tempietto del Clitunno), Giebel der Westfassade.

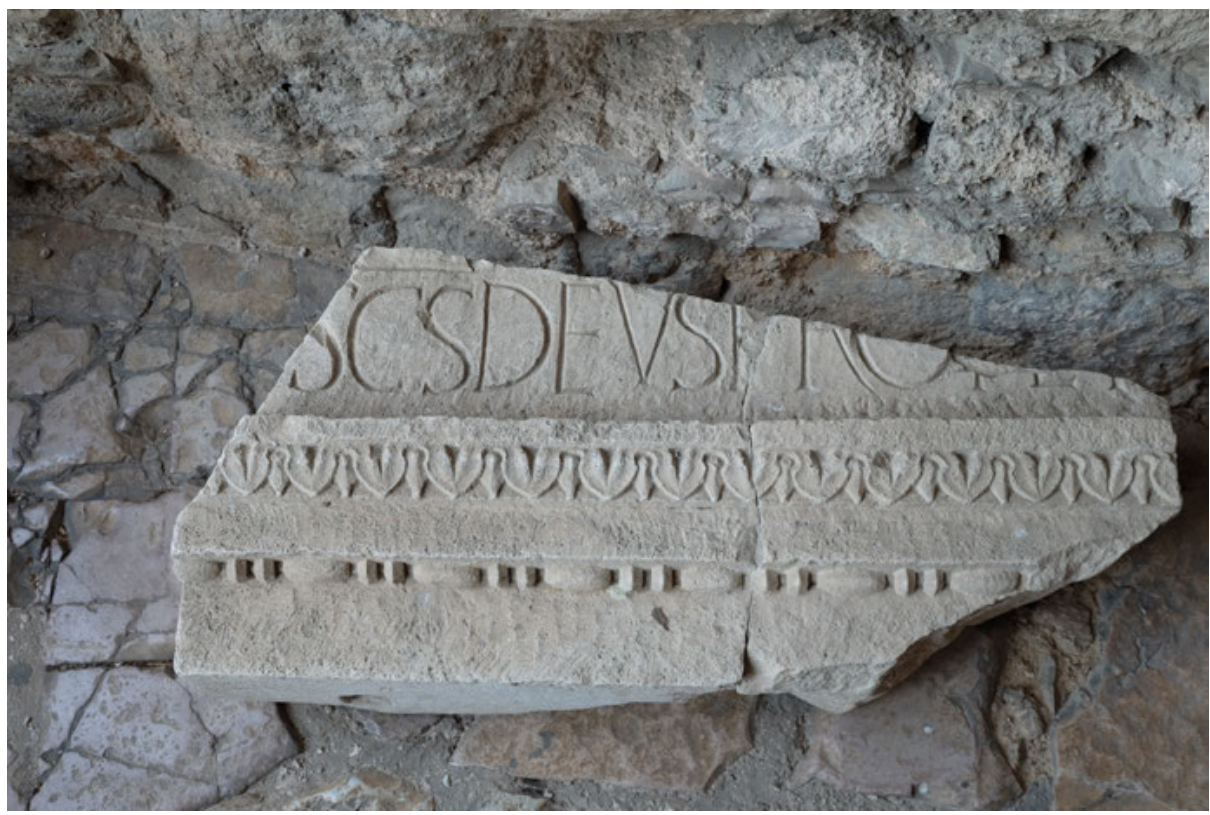

Abb. 3: San Salvatore di Pissignano (Tempietto del Clitunno), Fragment der Inschrift vom Giebel des nördlichen Eingangs. 
sen, ist der fast vollständige Rückgang dieser Gewohnheit unübersehbar, die wenigen Ausnahmen an Kirchengebäuden verdienen deshalb eine Betrachtung. Inhalt und Gestaltung der Texte unterscheiden sich von den antiken Vorbildern, und damit bleibt auch zu fragen, wer ihre Adressaten waren und wie sie dazu beitrugen, sakrale Schrifträume zu gestalten.

Kristina Krüger unterschied solche einzeiligen Fassadeninschriften von mehrzeiligen Inschrifttafeln, wie in Corvey, ${ }^{5}$ die eine eigene römische Tradition haben, im Mittelalter recht häufig bleiben ${ }^{6}$ und auch an Renaissancebauten eingesetzt wurden. ${ }^{7}$ Nachfolgend sollen nur lineare Fassadeninschriften „römischer Tradition“ in den Blick genommen werden, und ausgeklammert werden auch die durchaus bedeutsamen linearen Inschriften in sakralen Innenräumen, wie in den Pfalzkirchen in Salerno und Aachen. ${ }^{8}$ John Mitchell und Kristina Krüger haben viele dieser inschrifttragenden Monumente schon angesprochen. ${ }^{9}$

\section{Die Tempelfassade als ambivalentes Vorbild}

$\mathrm{Zu}$ den Grundüberzeugungen der Architekturgeschichte gehört die Aussage, dass christliche Kirchen zunächst bewusst auf die Übernahme des Fassadenmotivs antiker Tempel verzichtet haben, also auf monumentale Säulenstellungen, die einen Giebel tragen. ${ }^{10}$ In gleicher Weise hat man im Mittelalter darauf verzichtet, die Widmung des Kirchenbaus oder den Namen der Stifter in monumentaler Form an der Fassade zu präsentieren, sondern andere Positionen für Inschriften gesucht, die Künstler bzw. Auftraggeber nennen. ${ }^{11}$ Für Buchmalerei und Münzprägung gilt dieses Aussage freilich nicht: Von Säulen getragene Giebel sind dort spätestens seit karolingischer Zeit üblich, und auf Münzen wird die Tempelfront sogar mit der Legende Christiana religio kombiniert. $^{12}$

An den wenigen antiken Tempeln, deren Fassade unversehrt im Mittelalter bestehen blieb, weil - und obwohl - sie in christliche Kirchen oder Adelssitze umgewandelt wurden, fehlen heute die originalen Widmungs- bzw. Stifterinschriften, da die Metallbuchstaben entfernt wurden. Mittelalterliche Autoren haben zwar Bauinschriften an Stadttoren und zahlreiche Grabinschriften gelesen, es fehlen aber

5 Krüger 2014, 69f.

6 Lomartire 1984, 374-380.

7 Mardersteig 1959.

8 Zu Salerno: Natella 2000, 114; Peduto 2001, 661-665; Lambert 2013, 58f.; Krüger 2014, 68f.; zu Aachen: Scheins 1901; Giersiepen 1991, 6, Nr.6†; Bayer 1999.

9 Mitchell 1990; Krüger 2014, 66-69.

10 Brandenburg 2004, bes. 11-15.

11 Dietl 2009.

12 Kluge 1999. 
Belege dafür, dass sie auch Tempelinschriften rezipiert hätten. ${ }^{13}$ Im 16 . Jahrhundert waren die Texte jedenfalls noch lesbar: Frühneuzeitliche Architekten und Archäologen konnten sie sogar aus den Bohrlöchern zur Befestigung der vergoldeten Metallbuchstaben rekonstruieren. Meines Wissens fehlen präzise Forschungen, wie lange die antiken Inschriften auf den Fassaden noch einigermaßen vollständig vorhanden waren. Möglicherweise fielen sie schon früh dem Metallraub zum Opfer, so dass - bis zum Beginn ,archäologischer' Bauforschung in der Renaissance - nur ihre grundsätzliche Existenz im Bewusstsein geblieben war. Bei der vielerorts fassbaren, formal präzisen Nachbildung von Schmuckformen und Inschriften mit eingelegten Buchstaben ${ }^{14}$ scheint mir dies allerdings kein naheliegender Vorbehalt. Dass die Schriftquellen schweigen, belegt eher die mangelnde Relevanz des Inhalts solcher Tempelinschriften für mittelalterliche Kleriker, Gelehrte und Politiker. Ida Calabi Limentani hat aufgezeigt, dass Inschriften von Triumphbögen, Stadttoren und Grabmälern durchaus gelesen und auch weitgehend verstanden wurden. ${ }^{15}$

Der Tempel in Vienne (Abb.4), später als Marienkirche genutzt, trug nacheinander vier Inschriften, deren Lesung bis heute umstritten ist und die wohl den Weihetitel des Tempels nannten. ${ }^{16}$ In Nîmes trug der Fries der „Maison Carrée“ ebenfalls die Weiheinschrift: C(aio) CAESARI AUGUSTI F(ilio) CO(n)S(uli) L(ucio) CAESARI AUGUSTI F(ilio) CO(n)S(uli) DESIGNATO ${ }^{17}$ Am Pantheon in Rom, 609 von Papst Gregor I. in eine Marienkirche umgewandelt, war hingegen der Name des Stifters angebracht: M(arcvs) AGRIPPA L(vci) F(ilivs) CO(n)S(vl) TERTIVM FECIT (Marcus Agrippa, Sohn des Lucius, zum dritten Mal Consul, hat [den Tempel] erbaut). ${ }^{18}$ Erst die moderne Archäologie hat erkannt, dass die Inschrift auf einen früheren Stifter Bezug nimmt. Das Bauwerk selbst ist viel jünger und wurde unter den Kaisern Trajan und Hadrian zwischen etwa 114 und 128 neu erbaut. ${ }^{19}$ Eine zweite Inschrift, die die Wiederherstellung des Bauwerks im Jahr 202 durch die Kaiser Septimius Severus (193-211) und Caracalla (198-217) dokumentierte, wurde in zwei Zeilen auf dem Architrav eingehauen: IMP CAE L SEPTIMIVS SEVERVS PIVS PERTINAX ARABICVS ADIABENICVS PARTHICVS MAXIMVS PONTIF MAX TRIB POTEST X IMP XI COS III P P PROCOS ET / IMP CAES M AVRELIVS ANTONINVS PIVS FELIX AVG TRIB POTEST V COS PROCOS PANTHEVM VETVSTATE CORRVPTVM CVM OMNI CVLTV RESTITVERVNT. ${ }^{20}$ Mittelalterliche Menschen waren von dem riesi-

13 Clemens 2003, bes. 400-417.

14 Krüger 2014.

15 Calabi Limentani 1970.

16 Zuletzt André/Chalon 2012, gegen ältere Lesungen: Corpus Inscriptionum Latinarum 12, Nr. 1845; Formigé 1924.

17 Corpus Inscriptionum Latinarum 12, Nr. 3156; zum Bau: Amy/Gros 1979.

18 Eroli 1895, 380-382 Nr. II.

19 Zum Bau: Waddell 2008.

20 Eroli 1895, 382f. Nr. III. 


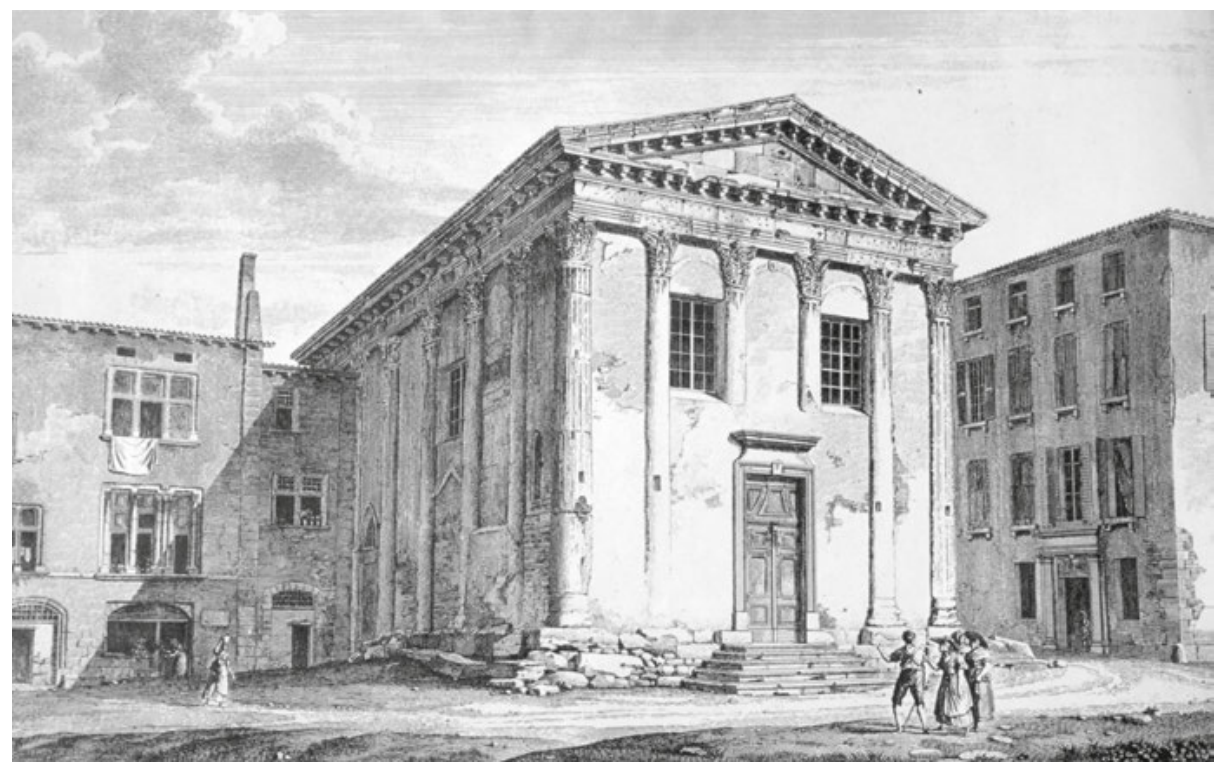

Abb. 4: Vienne, Notre Dame-de-la-Vie, ehemaliger römischer Tempel, vor der Freilegung; Stahlstich $1816 / 36$.

gen Kuppelbau und seiner demonstrativ sichtbar belassenen antiken Vergangenheit fasziniert; ${ }^{21}$ die ehemalige Monumentalinschrift fand nur bei Cimabue ein gewisses Interesse, der allerdings in seiner Darstellung von Italien (Ytalia) neben dem Evangelistenbild des hl. Markus in San Francesco in Assisi offenbar auf den zweiten, darunter eingehauenen Text Bezug nahm. ${ }^{22}$

Der Blick auf die Fassadeninschriften antiker Tempel zeigt jedenfalls, dass dort die religiösen Formeln des „Tempietto del Clitunno“ keineswegs ihr Vorbild fanden und dies gilt auch für die nachfolgend zu betrachtenden Fassadeninschriften: Antikenrezeption lässt sich im 8./9. Jahrhundert fassen in der Tatsache der Anbringung einer Inschrift an der Fassade und speziell am Giebelfuß, prägte aber nicht Inhalt und Gestaltung der Texte.

21 Buddensieg 1971.

22 Andaloro 1985, 161-163, bes. Anm. 146. 


\section{Fassadeninschriften an Kirchen des 9.-12. Jahrhunderts}

Am nördlichen Rand des Langobardenreichs von Benevent entstand im frühen 9. Jahrhundert die große, einsam im Apennin gelegene Abteikirche von San Vincenzo al Volturno. Johannes, Autor des Chronicon Vulturnense, schreibt um 1130/40 ihre Errichtung Abt Josua (792-817) zu. Die zum Atrium gerichtete Fassade der Kirche (in ecclesiae fronte) trug die Inschrift QVAEQVE VIDES OSPES PENDENCIA CELSA VEL IMA VIR DOMINI IOSVE STRVXIT CVM FRATRIBVS VNA (Was Du Hängendes siehst, Gast, oben oder unten, hat der Gottesmann Josua zusammen mit den Brüdern erbaut). ${ }^{23}$ Die Buchstabenfolgen QV[AEQVE], [VI]R DO[MINI] und [IOSV] E S[TRUXIT] sind auf ca. 30 Marmorfragmenten mit $30 \mathrm{~cm}$ (= 1 Fuß) hohen langobardischen Kapitalisbuchstaben erhalten (Abb.5), die im opus-sectile-Fußboden der nach 1100 in einiger Entfernung neu gebauten, romanischen Klosterkirche eingesetzt worden waren. ${ }^{24}$ Die Lettern bestanden aus vergoldetem Metall und waren eingedübelt. Die Versinschrift spricht direkt den Besucher an, sie rühmt das Bauwerk und nennt den Namen des Bauherrn. Dass auch die Mönchsgemeinde angesprochen ist, dürfte deren starke Position neben dem Abt deutlich machen. Religiöse Konnotati-

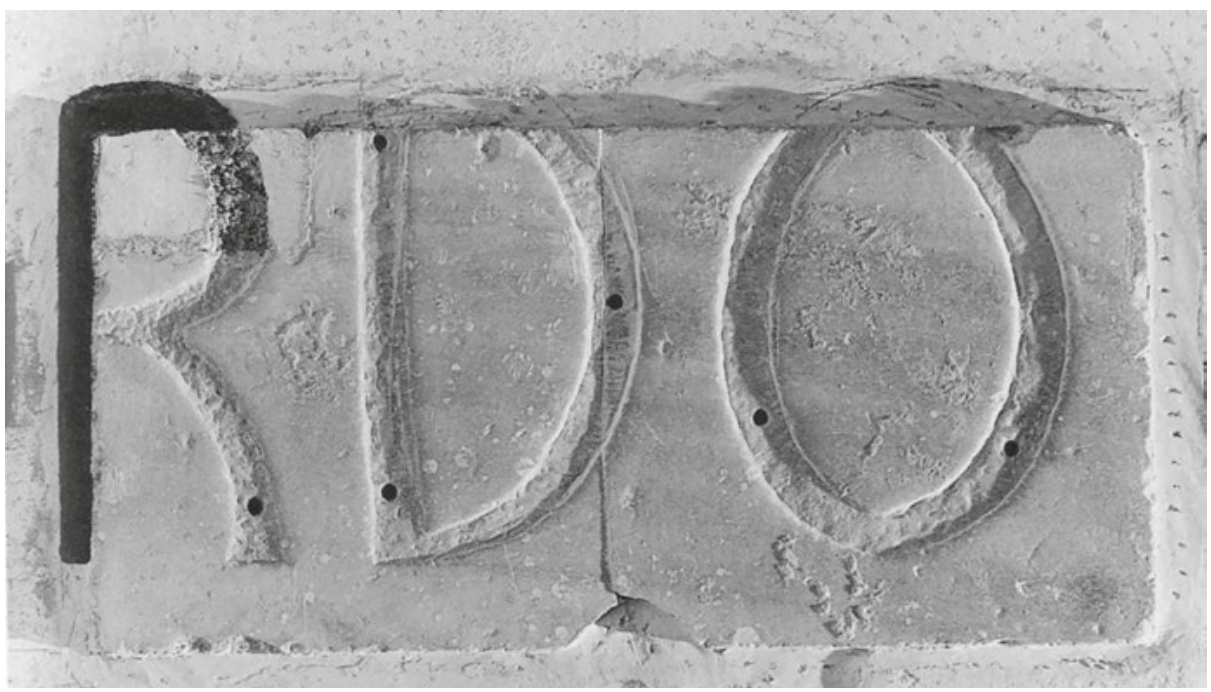

Abb. 5: San Vincenzo al Volturno, Fragmente der Fassadeninschrift.

23 Federici, Chronicon, Bd.1, 221. - Für Hinweise zur problematischen Deutung von pendencia celsa vel ima danke ich Tino Licht.

24 Pantoni 1962; Mitchell 1990, 205-209; Mitchell 1994, 916-919; Hodges 1996, 36; Mitchell 1999; Krüger 2014, 66-68. 
onen hat der Text nicht, vom Titel des Abts abgesehen, dessen Bezeichnung als vir domini wohl dem Versmaß geschuldet ist. Die Länge der überlieferten Inschrift von ca. $14,5 \mathrm{~m}$ zeigt, dass sie nur Mittelschiffbreite hatte. John Mitchell rekonstruiert sie deshalb unterhalb des mittleren Giebels, in der Art einer Tempel-Fassadeninschrift (Abb.6). Weitere Fragmente belegen, dass es in diesem Kloster mindestens eine zweite Monumentalinschrift mit vergoldeten Lettern gab. ${ }^{25}$
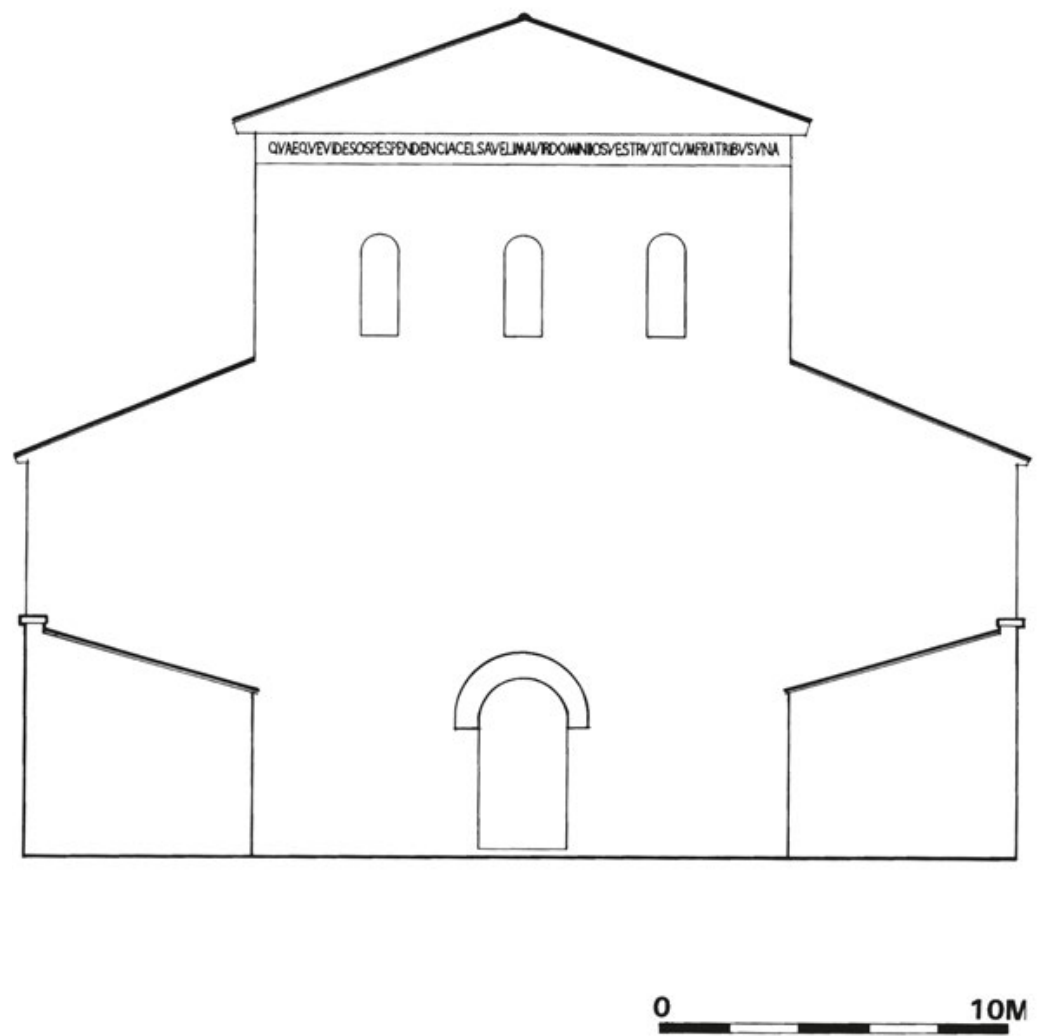

Abb.6: San Vincenzo al Volturno, Ostfassade der Klosterkirche, Rekonstruktion von John Mitchell.

John Mitchell hat die Besonderheit der Inschrift von San Vincenzo in der frühmittelalterlichen klösterlichen und herrschaftlichen Kultur herausgestellt, ${ }^{26}$ vornehmlich für die Verwendung von vergoldeten Lettern, aber ohne Blick auf den Habitus und den rekonstruierten architektonischen Kontext. Vor der Kirchenfassade lag ein

25 Mitchell 1990, 209f.; Krüger 2014, 67f.

26 Mitchell 1990, 210-225. 
großer, architektonisch aufwändig terrassierter Vorhof (Abb.7). Unter diesem Vorhof wurde der Zugang zum Kloster durchgeführt, Treppen führten zum Hof hinauf. Er war also nicht einfach ein abgeschrankter Vorplatz, sondern ein eigener hypäthraler Sakralbereich. Ob dieser Vorhof zeitgleich mit dem Kirchenbau war oder erst im späten 10. Jahrhundert entstand, ist noch umstritten. ${ }^{27}$

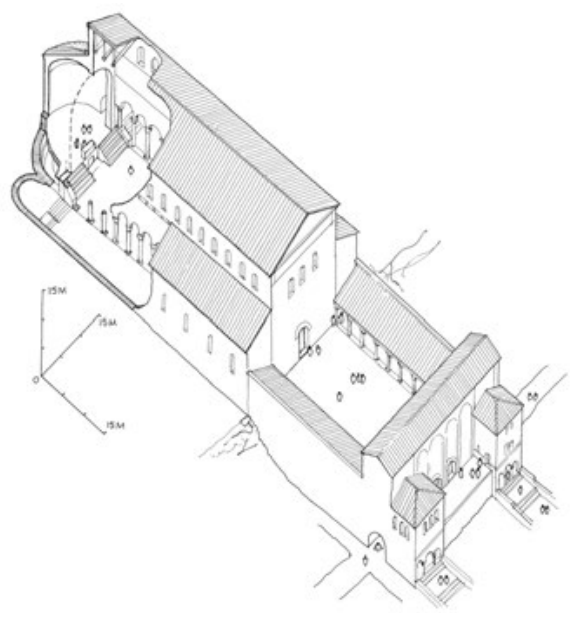

Abb.7: San Vincenzo al Volturno, isometrische Rekonstruktion von Klosterkirche und Atrium.

Nur in wenigen Regionen Italiens wurden friesartige Stifterinschriften an Kirchenfassaden im späten 11. Jahrhundert wieder eingesetzt. Das älteste, bekannte Beispiel ist der 1084 geweihte Dom von Salerno (Abb. 8-9). Am Giebelfuß steht: M(atthaeo) A(postolo)] ET EVANGELISTAE PATRONO VRBIS ROBBERTVS DVX R(omani) IMP(erii) MAXIM[VS TRIV]MPHATOR DE AERARIO PECVLIARI (Dem Apostel und Evangelist Matthäus, Stadtpatron, [ließ die Kirche erbauen] Herzog Robert, des römischen Reichs größter Triumphator, aus dem eigenen Vermögen). ${ }^{28}$ Der normannische Feldherr Robert Guiscard (†1085) hatte 1076 Salerno erobert und 1084 den von Kaiser Heinrich IV. in Rom festgesetzten Papst Gregor VII. befreit. Dieser ging nach Salerno ins Exil und weihte dort die neue Kathedrale, in der er nach seinem Tod 1085 auch beigesetzt wurde. Der Domfassade vorgelagert ist ein großes, von Säulengängen umstandenes Atrium (Abb. 10). Die Situation der Inschrift entspricht also der Klosterkirche von San Vincenzo. Ihr Inhalt ist allerdings in der damaligen politischen Situation weniger selbstverständlich: Herzog Robert hatte Salerno und Rom gerade erst

27 Marazzi 2008; Marazzi 2010, XXXVIIIf. gegen Mitchell 1990. - Die neue Deutung des Grabungsbefunds, dass die große Basilika im 9. Jahrhundert lediglich ein kleines Portal auf der klosterzugewandten Südseite hatte (Marazzi 2008 mit Abb. 7; Marazzi 2014, Abb.38-40), erweckt erhebliche Zweifel, auch wenn positive Befunde für Portale in der Ostfassade fehlen.

28 Eine fachgerechte Edition der teilweise ergänzten Inschrift fehlt; vgl. vorerst Mitchell 1990, $214 f$. 


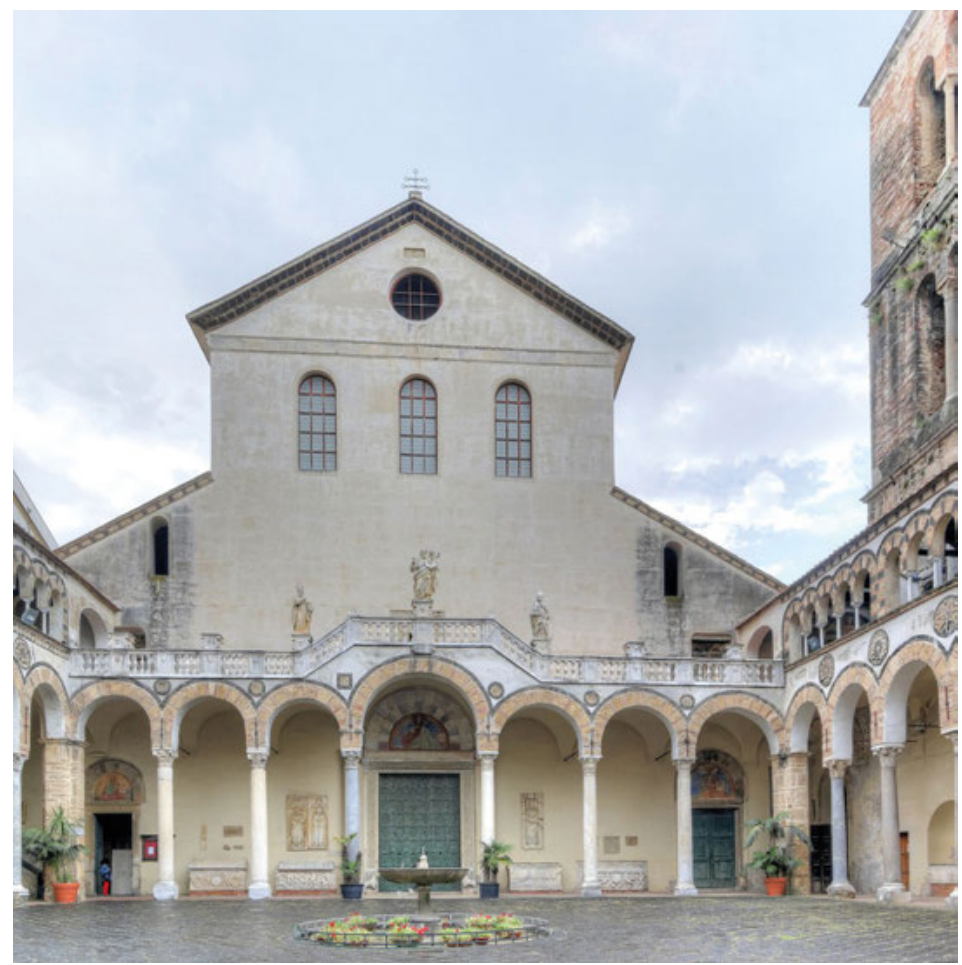

Abb. 8: Salerno, Duomo, Westfassade und Atrium.

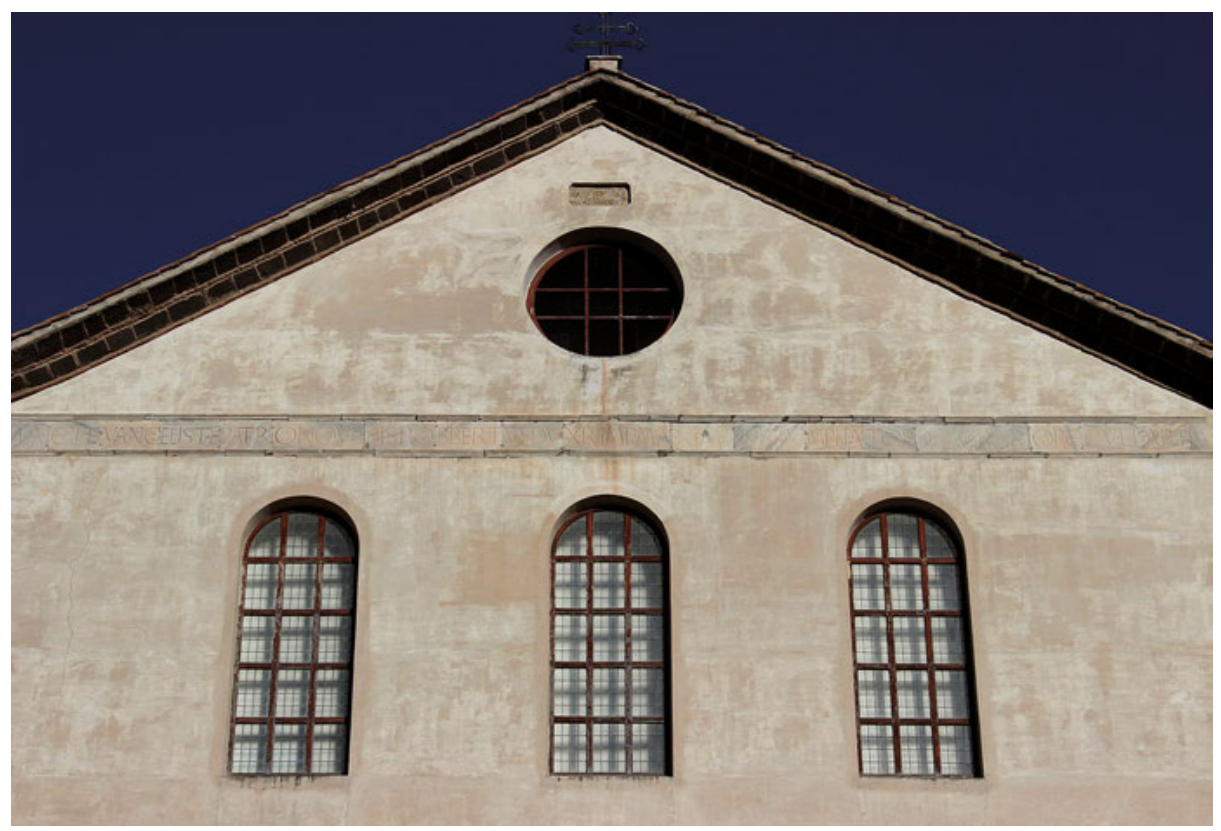

Abb. 9: Salerno, Duomo, Westfassade, Inschrift auf dem Fries unter dem Giebel. 


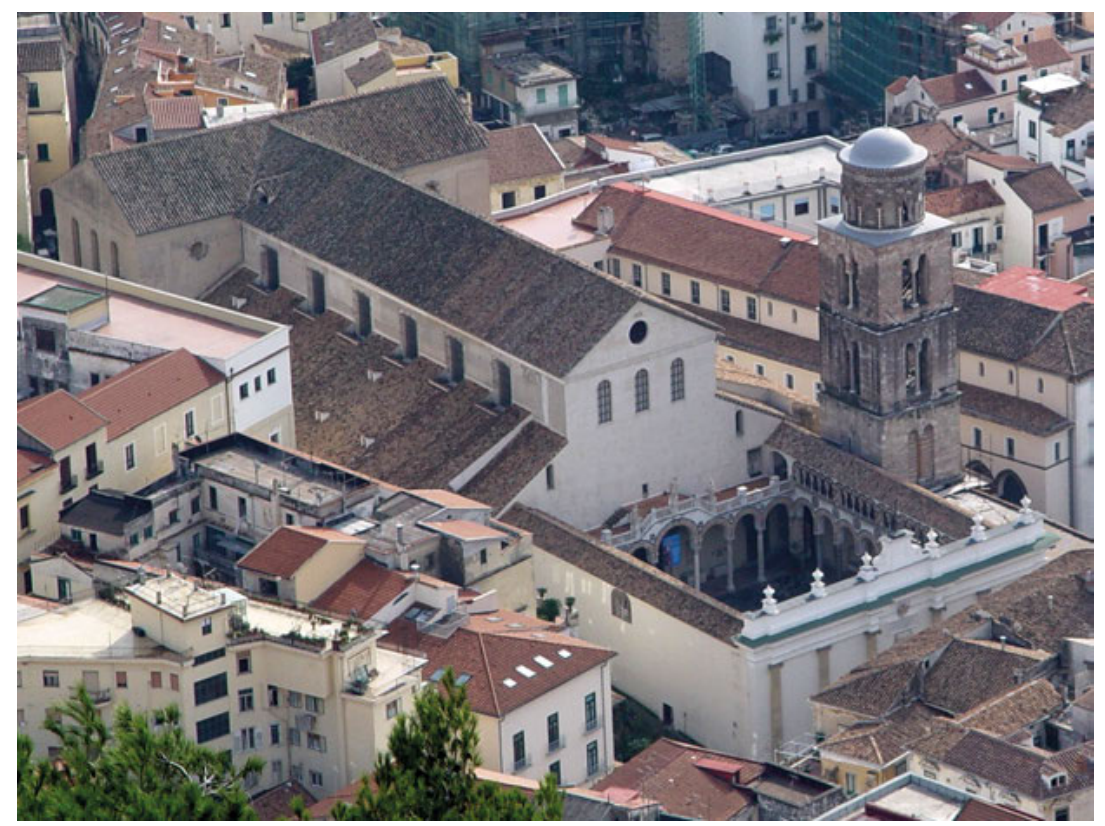

Abb.10: Salerno, Duomo, Blick vom Cole Bonadies auf Atrium und Westfassade.

gewaltsam in Besitz genommen. Mit der Weihe an den Stadtpatron Matthäus stellt er sich demonstrativ in die Nachfolge der früheren, rechtmäßigen Herrscher und betont zugleich seinen Triumph. Die Abkürzung des Heiligennamens ist dabei eine im christlichen Kontext bis dahin ganz unübliche, sakralisierende Hervorhebung, die sich in die Nachfolge der antik-römischen Epigraphik stellt. ${ }^{29}$

An anderen Kirchen wurden Fassadeninschriften nicht auf einen ausgeschiedenen Bezirk bezogen. Sie sind heute - und wohl schon ursprünglich - von öffentlichen Plätzen aus lesbar.

An der toskanischen Stiftskirche Sant'Andrea in Empoli (Abb. 11) steht die Friesinschrift auf dem architravartigen Gesims zwischen Sockelgeschoss und Obergeschoss der inkrustierten Fassadengliederung. Die Buchstaben sind hier nicht auf dem Fries, sondern auf der obersten Fascie des Architravs eingehauen (Abb.12): HOC OPVS EXIMII PRAEPOLLE[NS ARTE] MAGISTR[I] BIS [NOVIES LVST]RIS ANNIS TAM MILLE PERACTIS AC TRIBVS EST CEPTVM POST NATVM VIRGINE VERBVM QVOD STVDIO FRATRVM SVMMOQ(ve) LABORE PATRATVM CONSTAT RODVLFI BONIZONIS PRESBITERORVM ANSELMI ROLANDI PRESBITERIQ(ve) GERARDI VNDE DEO CARI CREDVNTVR ET AETHERE CLARI (Dieses Werk, das durch die Kunst des hervorragenden Magisters überaus glänzt, ist begonnen worden, nachdem zweimal neun Jahrfünfte sowie tausend und drei Jahre [= 1093] seit der Fleischwer-

29 Calabi Limentani 1970. 


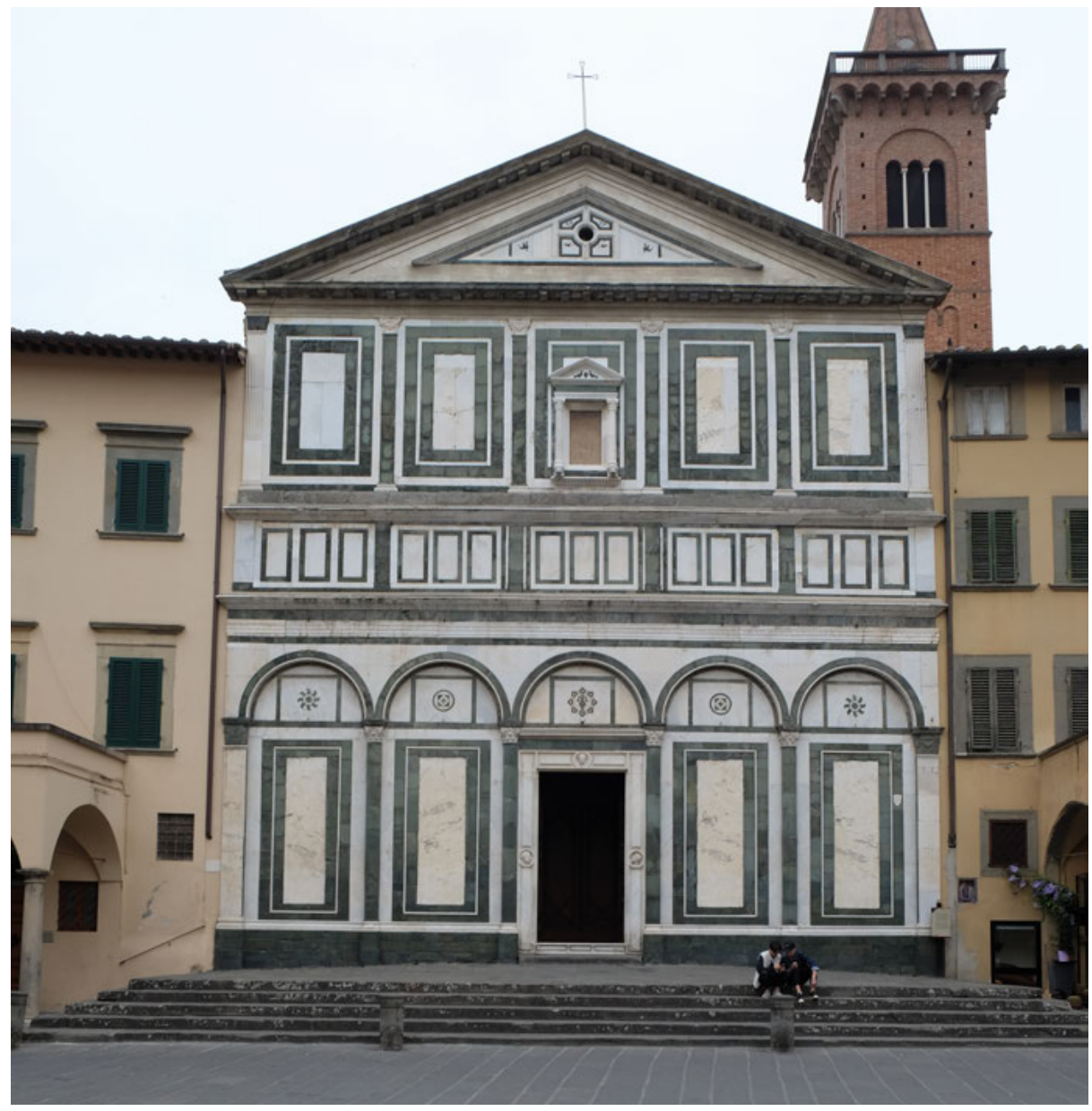

Abb.11: Empoli, Sant'Andrea, Westfassade.

dung des Worts aus der Jungfrau abgelaufen waren. Dank der Mühe und der größten Anstrengung der Brüder Rodulfus und Bonizo, der Priester Anselmus und Rolandus und des Priesters Gerardus steht das Werk vollendet da, weshalb man sie für gottgeliebt und im Himmel bekannt hält). ${ }^{30}$ Da das Kirchengebäude selbst im 18. Jahrhundert neugebaut und der obere Teil der Fassade erst 1802 ausgeführt wurden, bleibt unklar, ob die Inschrift den Bau der Kirche oder nur den der kostbaren Marmorinkrustation zum Thema hat. In ihrer Ausführlichkeit und der gesuchten Schwierigkeit der Datumsangabe steht sie im Kontext zeitnaher Inschriften von Marmorwerkstätten ${ }^{31}$ trotz ihrer Position gewinnt sie nicht den Charakter einer Monumentalinschrift.

30 Dietl 2009, 807.

31 Grundlegend: Claussen 1987. 

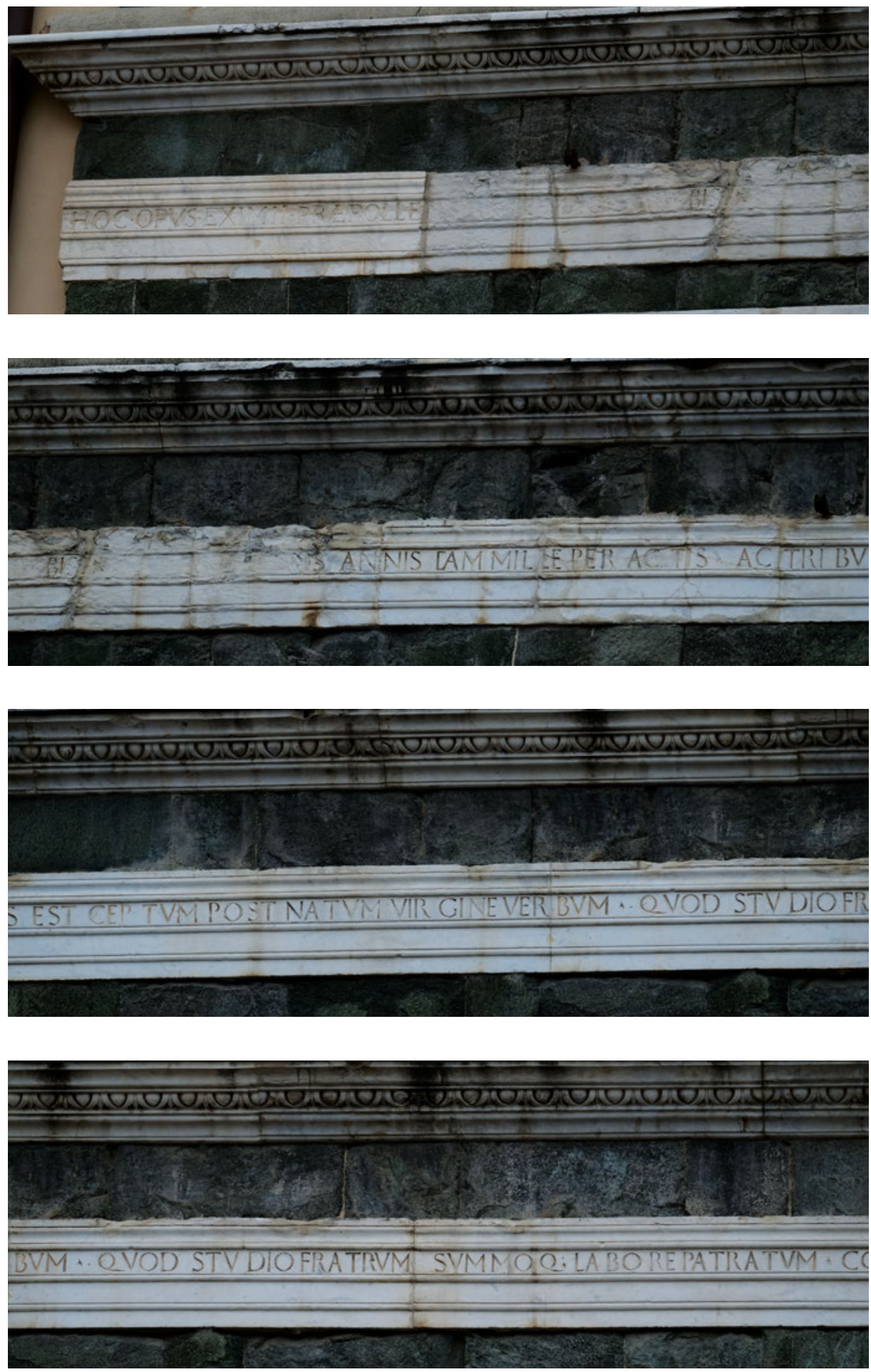

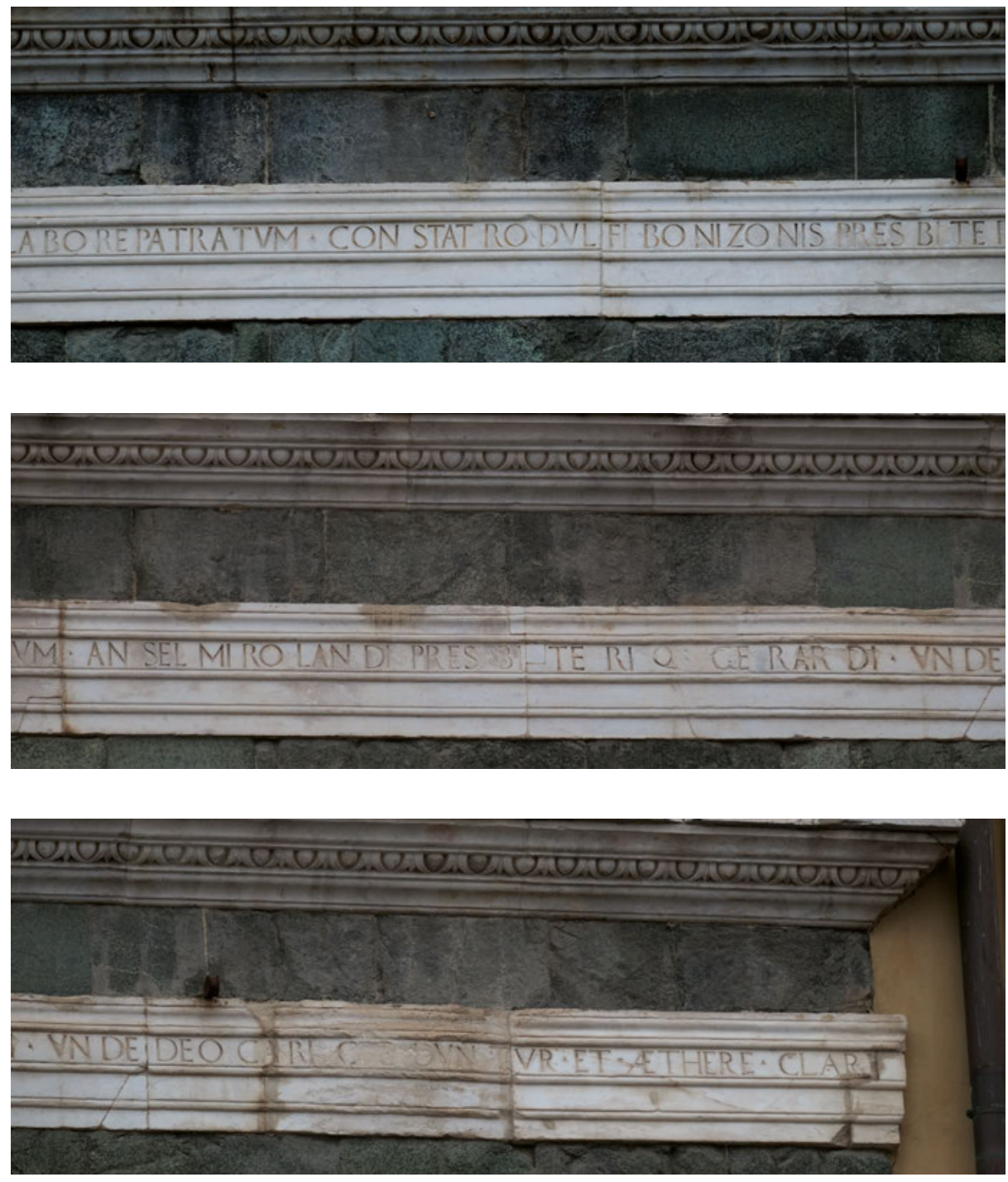

Abb.12.1-7: Empoli, Sant'Andrea, Westfassade, Inschrift auf dem Architrav des Stockgesimses. 
Gar nicht in das Gliederungssystem der Architektur eingebunden ist die Fassadeninschrift auf der Westfassade der Domkirche San Feliciano in Foligno (Abb.13). In der hellrot und weiß gebänderten Quaderung trägt eine weiße Quaderlage oberhalb des Hauptportals die zweizeilige Inschrift (Abb.14): ANNO MILLENO CENTENO TER MONO DENO HEC DOMVS ALMA PATRIS CV(m) SANCTO FLAMINE NATI TEMPESTATE FAMIS NIMIE CEPIT RENOVARI A DOMINO FACTO CALIXTO PRESVLE MARCO / EXTITIT VIR MAGNVS LOTHOMVS ACTO CHOMARCVS QVOS CHRISTVS SALVET BENEDICAT ADIVVET AMEN (Im Jahr 1133 begann diese ehrwürdige Kirche des Vaters desjenigen, der mit dem heiligen Geist gezeugt war, erneuert zu werden, zur Unglückszeit einer strengen Hungersnot, durch das Wirken des Marcus, Bischof auf Geheiß des Herrn Calixtus / Es trat besonders der große Mann, der Baumeister und Bürgermeister Acto hervor. Sie möge Christus erretten, segnen und unterstützen. Amen). ${ }^{32}$ Die Buchstaben der zweiten, deutlich kürzeren Textzeile sind mit größeren Abständen gesetzt, so dass sie ebenfalls die ganze Fassadenbreite einnehmen.

Unweit von Foligno, und zugleich nur wenig entfernt vom bereits genannten, frühmittelalterlichen „Tempietto del Clitunno“, wurde im 12. Jahrhundert die Benediktinerabteikirche Bovara erbaut. ${ }^{33}$ Der von einem Konsolfries gerahmte Giebel der Westfassade (Abb.15) zeigt in flachem Relief eine große Blattranke, für die erkennbar der Westgiebelschmuck des „Tempietto“ als Vorbild gedient hatte. Am Giebelfuß, unmittelbar unter dem Konsolfries, aber ohne eigene architektonische Rahmung steht in zwei Verszeilen mit ca. $21 \mathrm{~cm}$ hohen Buchstaben (Abb.16): ATTO SVA DEXTRA TEMPLVM FECITQ(ve) FENESTRARVM / CVI DEVS ETERNAM VITAM TRIBVATQ(ve) SVPERNAM (Atto hat mit seiner Rechten die Kirche und das Fenster gemacht, dem Gott ewiges und höchstes Leben zuteil werden lasse). ${ }^{34}$ Eine Jahreszahl fehlt, ebenso jeder Hinweis auf den Auftraggeber. Im Kontext der bislang vorgestellten Beispiele ist zu vermuten, dass es ursprünglich eine zweite, noch unbekannte Inschrift gab, die diese Informationen darbot. Die mögliche Identität des hier genannten Atto mit dem im nahen Foligno genannten Baumeister Acto dürfte für eine - von den Formen der Architektur durchaus naheliegende - Datierung um 1130 sprechen. Die architektonische Disposition der ursprünglich ortsfern gelegenen Klosteranlage ist im heutigen, nachbarocken Zustand nicht mehr ablesbar und völlig unerforscht.

32 Dietl 2009, 873.

33 Toccaceli 1996/97.

34 Dietl 2009, 676. 


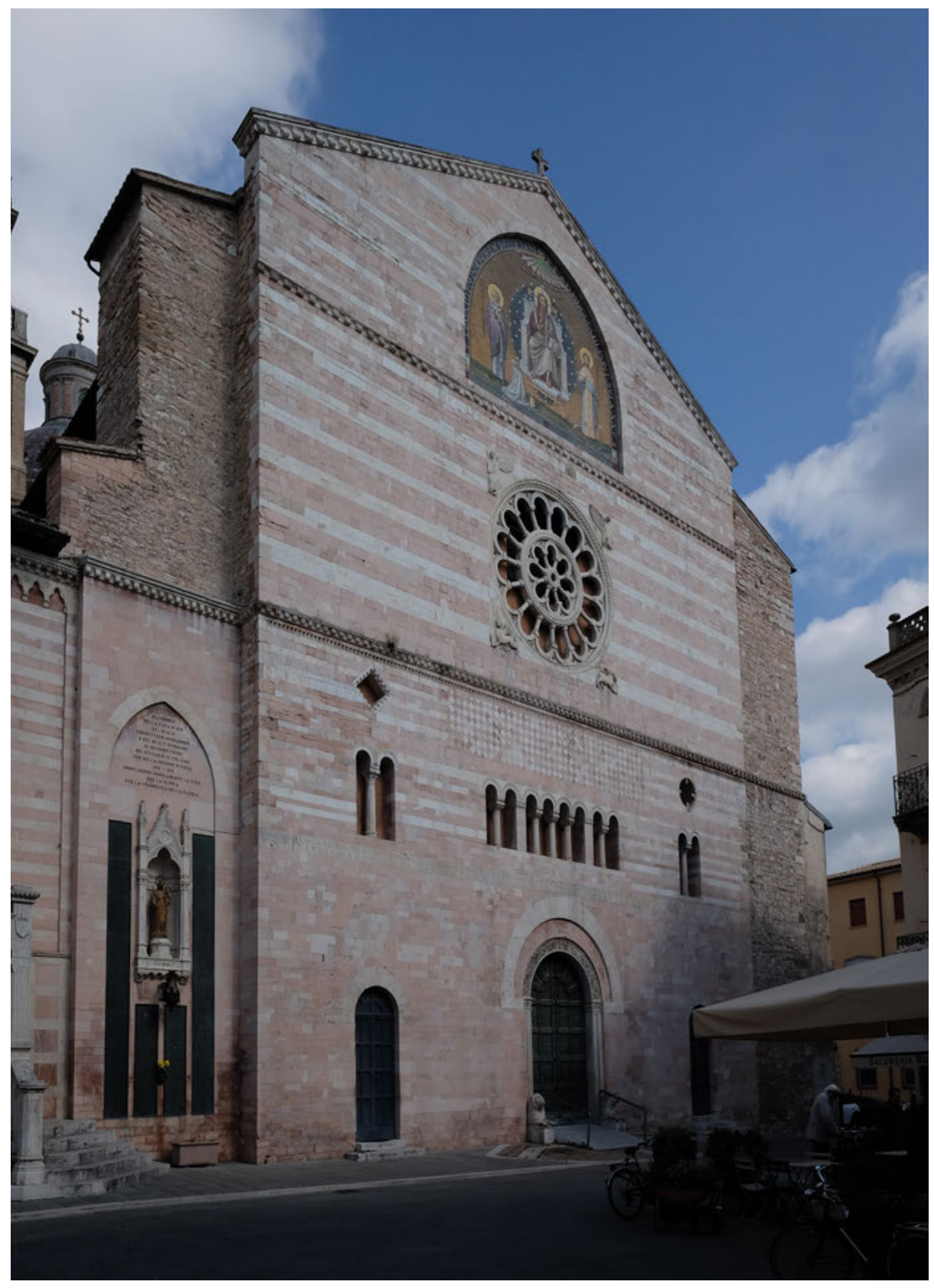

Abb.13: Foligno, Duomo San Feliciano, Westfassade. 

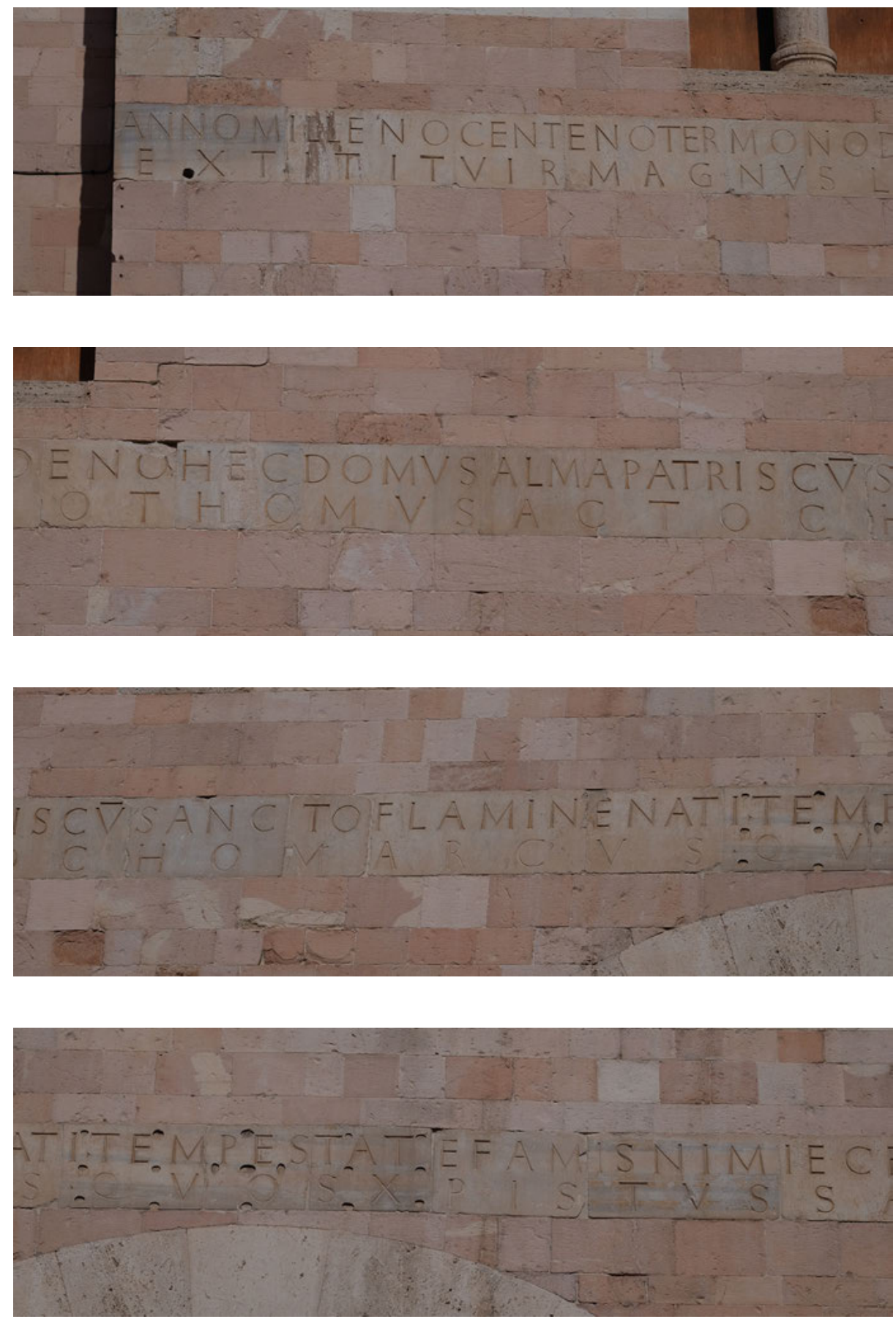

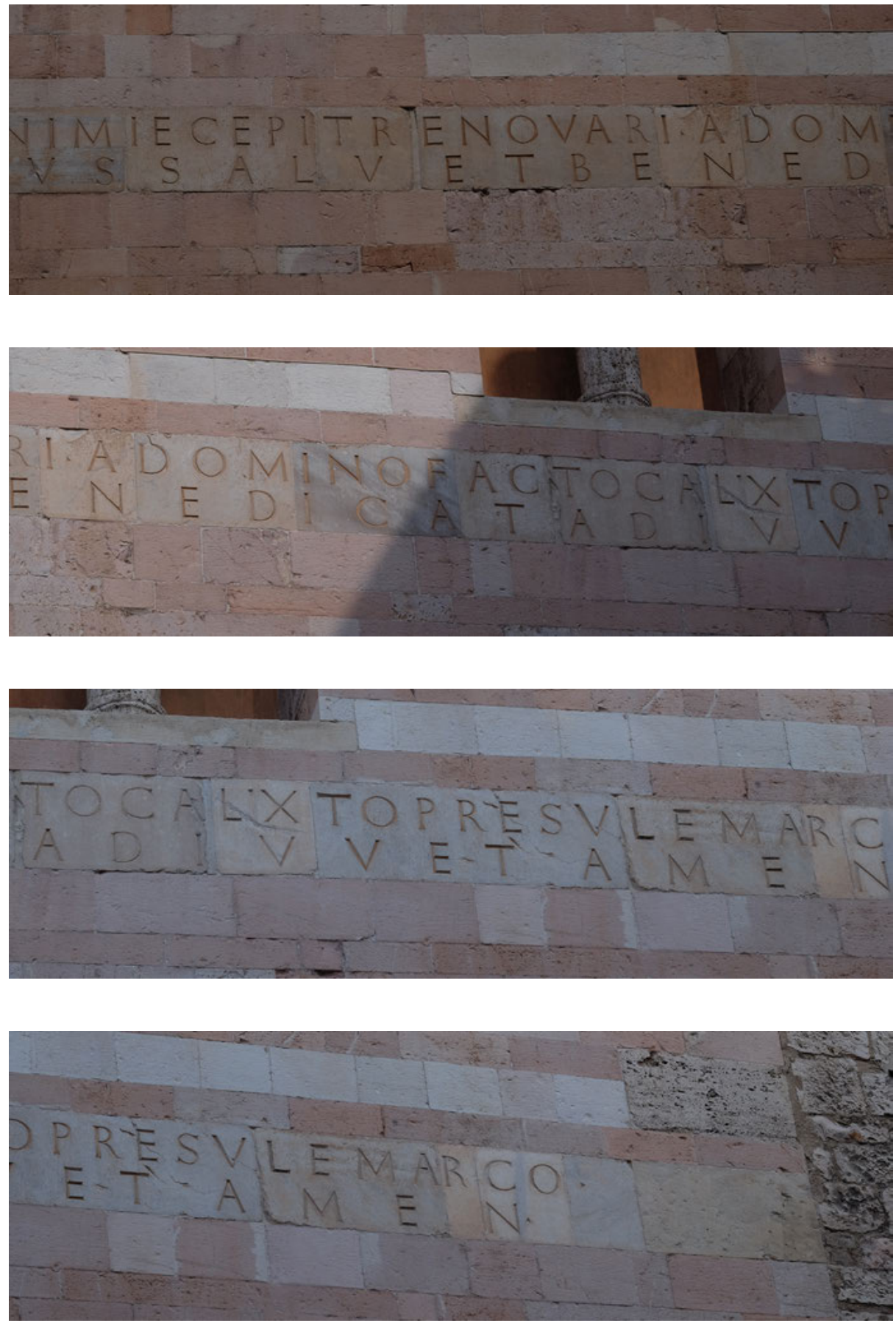

Abb.14.1-8: Foligno, Duomo San Feliciano, Westfassade, Inschrift auf der Wandfläche der Erdgeschosszone. 


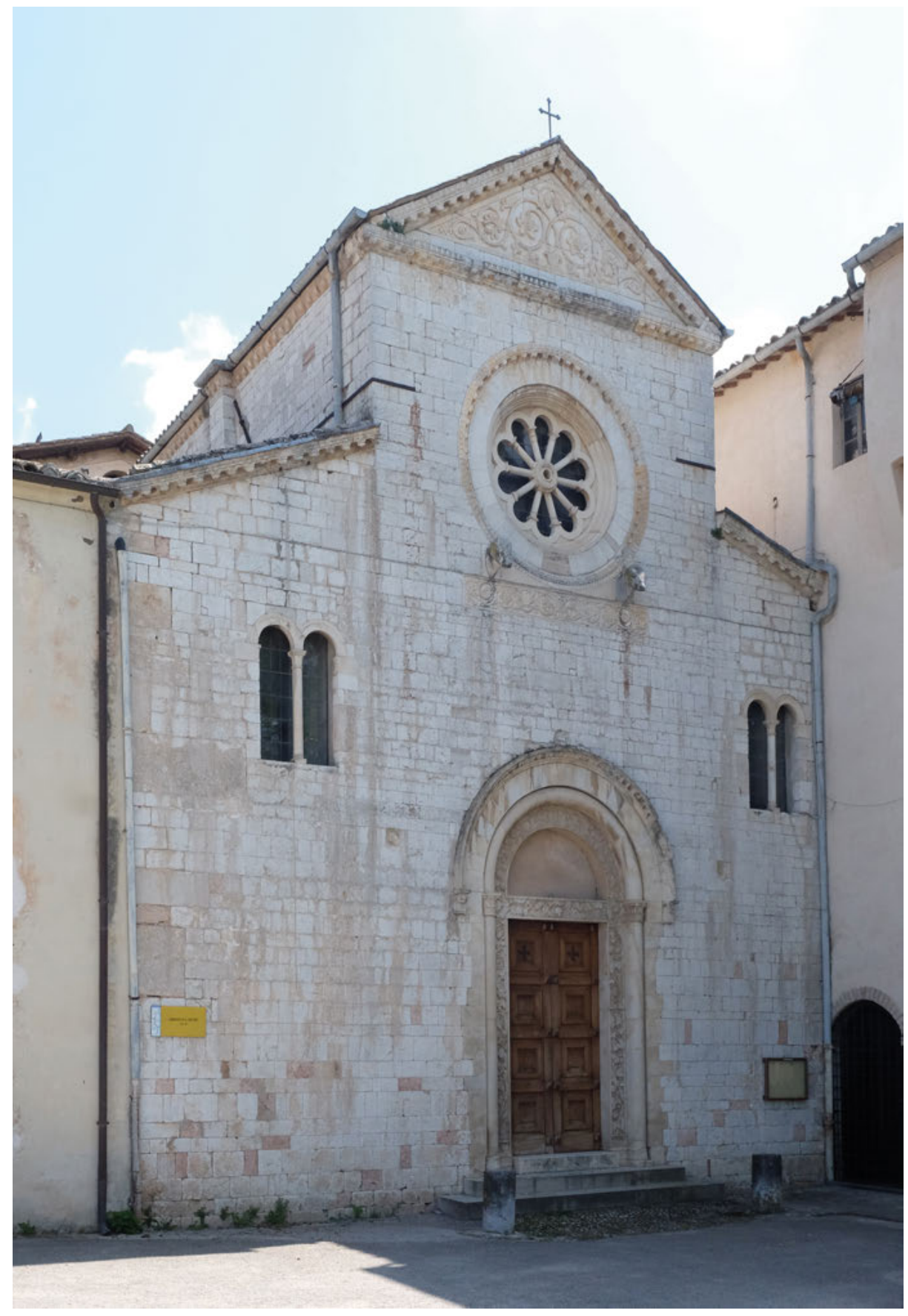

Abb. 15: Bovara, Abteikirche, Westfassade. 


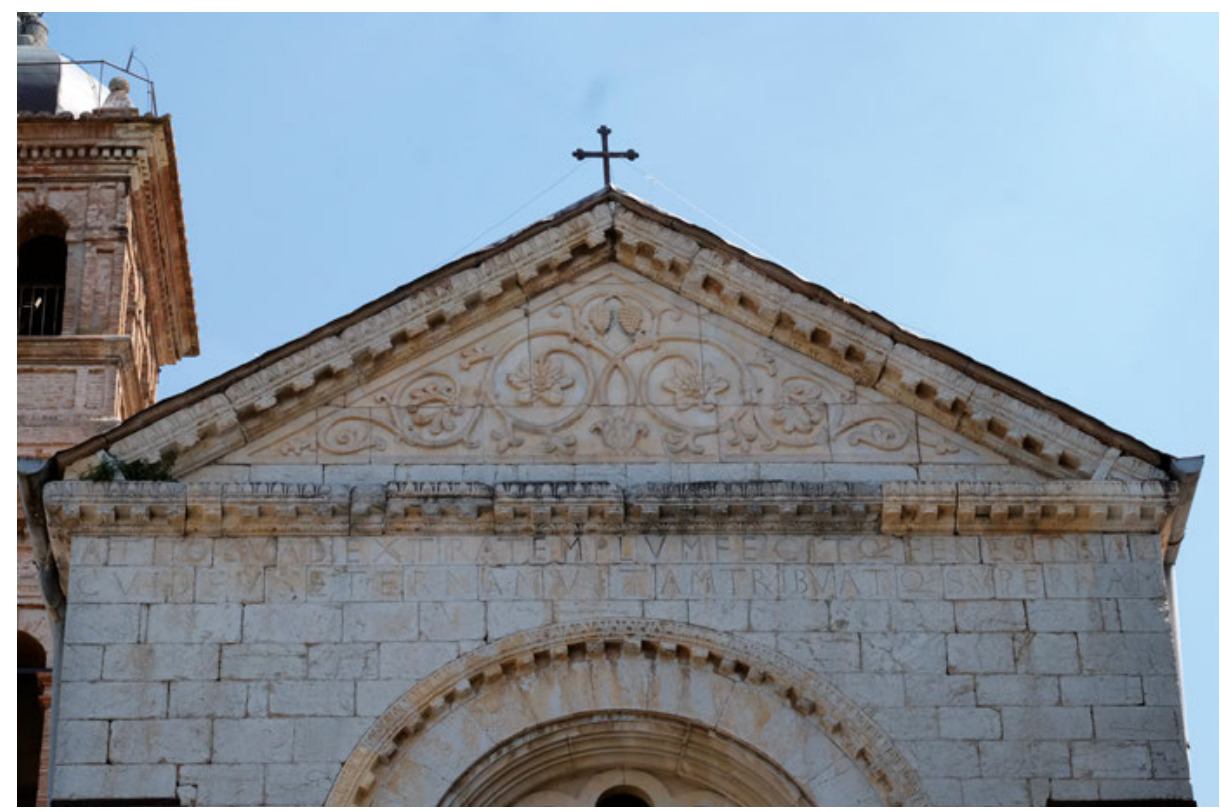

Abb.16: Bovara, Abteikirche, Westfassade, Inschrift unter dem Giebelgesims.

\section{Architrav-Inschriften an Vorhallen mittelalterlicher Kirchen}

Frei vor der Fassade aufgestellte Säulen tragen an Kirchenbauten der Spätantike, des frühen und des hohen Mittelalters, soweit dies erhaltene Monumente zeigen, in aller Regel keinen Giebel, sondern lediglich das waagerechte Pultdach einer Vorhalle. ${ }^{35}$ Der dahinter aufragende Giebel der Kirche erhielt zunächst ebenfalls keine tempelartige Gliederung. Reicher Bildschmuck, wie auf der Fassade von Alt St. Peter in Rom, die in einer Zeichnung des 11. Jahrhunderts überliefert ist, ${ }^{36}$ war außerhalb von Rom allerdings selten. Die mosaizierte Fassade von S. Maria in Trastevere in Rom (Abb.17) ${ }^{37}$ lässt die Wirkung erahnen - auch dort wurde keine Tempelfassade nachgebildet, und es fehlt gleichermaßen eine monumentale Inschrift.

35 Die Rekonstruktion einer Tempelfassade für die durch Kaiser Konstantin dem Großen gestiftete Rotunde über dem leeren Grab Christi in Jerusalem ist nicht im Befund gesichert; ausdrückliche Kritik an den Rekonstruktionen von Charles Coüasnon (Coüasnon 1974, Taf. 17) wurde allerdings noch nicht formuliert (vgl. Krüger 2000, 55-60).

36 „Codex Farfensis“: Johannes Diaconus, Vitae s. Gregorii libri IV, Eton College Library, Ms. 124, fol.122r; dazu Nilgen 1999.

37 Kuhn-Forte 1997, 699-825, hier 737-739. 


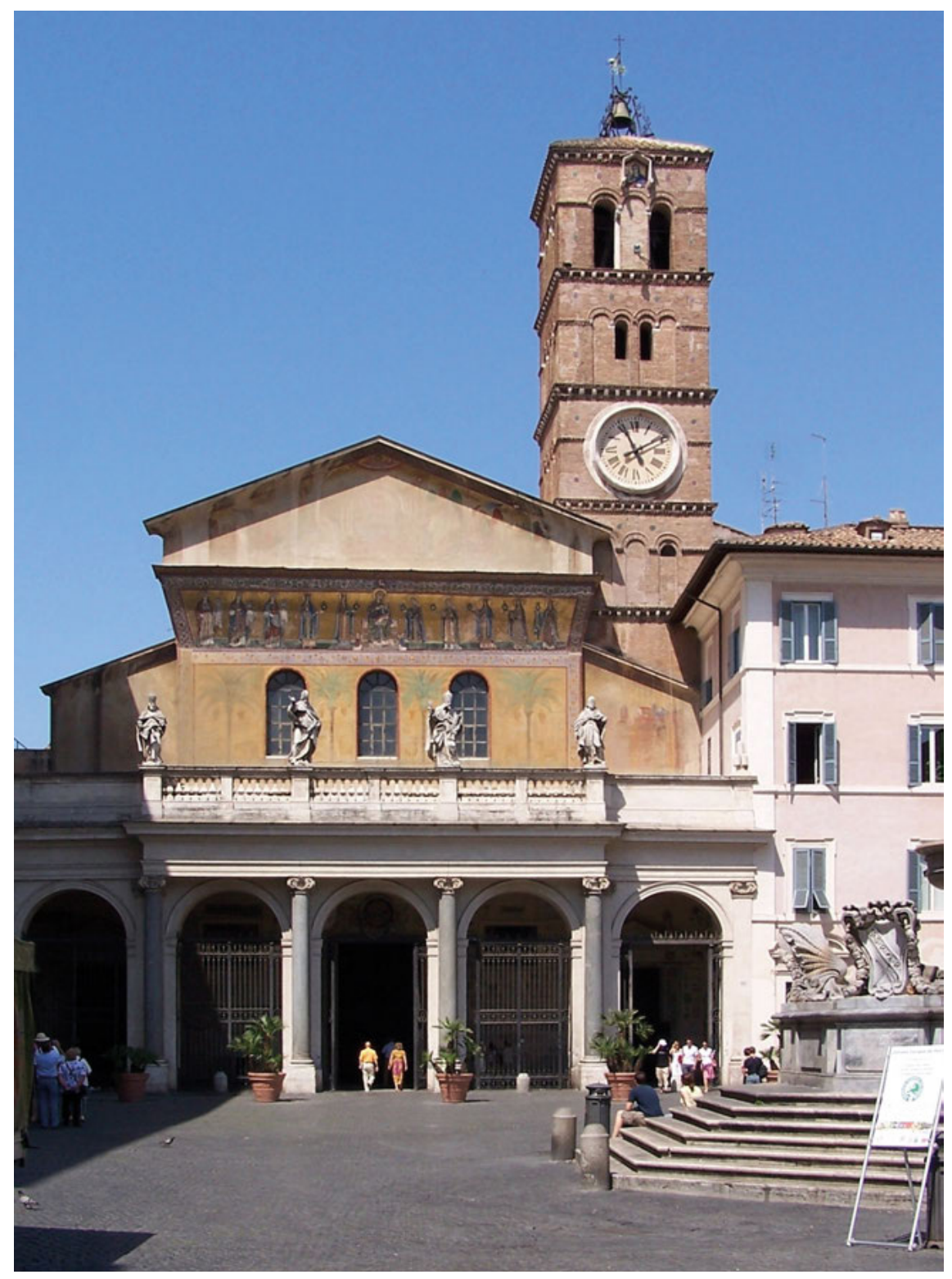

Abb.17: Rom, Santa Maria in Trastevere, Fassade.

Am Dom von Civita Castellana (Latium) erhielt die Westfassade eine dreiteilige Vorhalle, mit seitlichen ionischen Kolonnaden und einem zentralen, von korinthischen Pilastern getragenen, triumphbogenartigen Eingang (Abb.18). ${ }^{38}$ Das Gebälk des erhöh-

38 Claussen 1987, 82-91; Claussen 2012. 


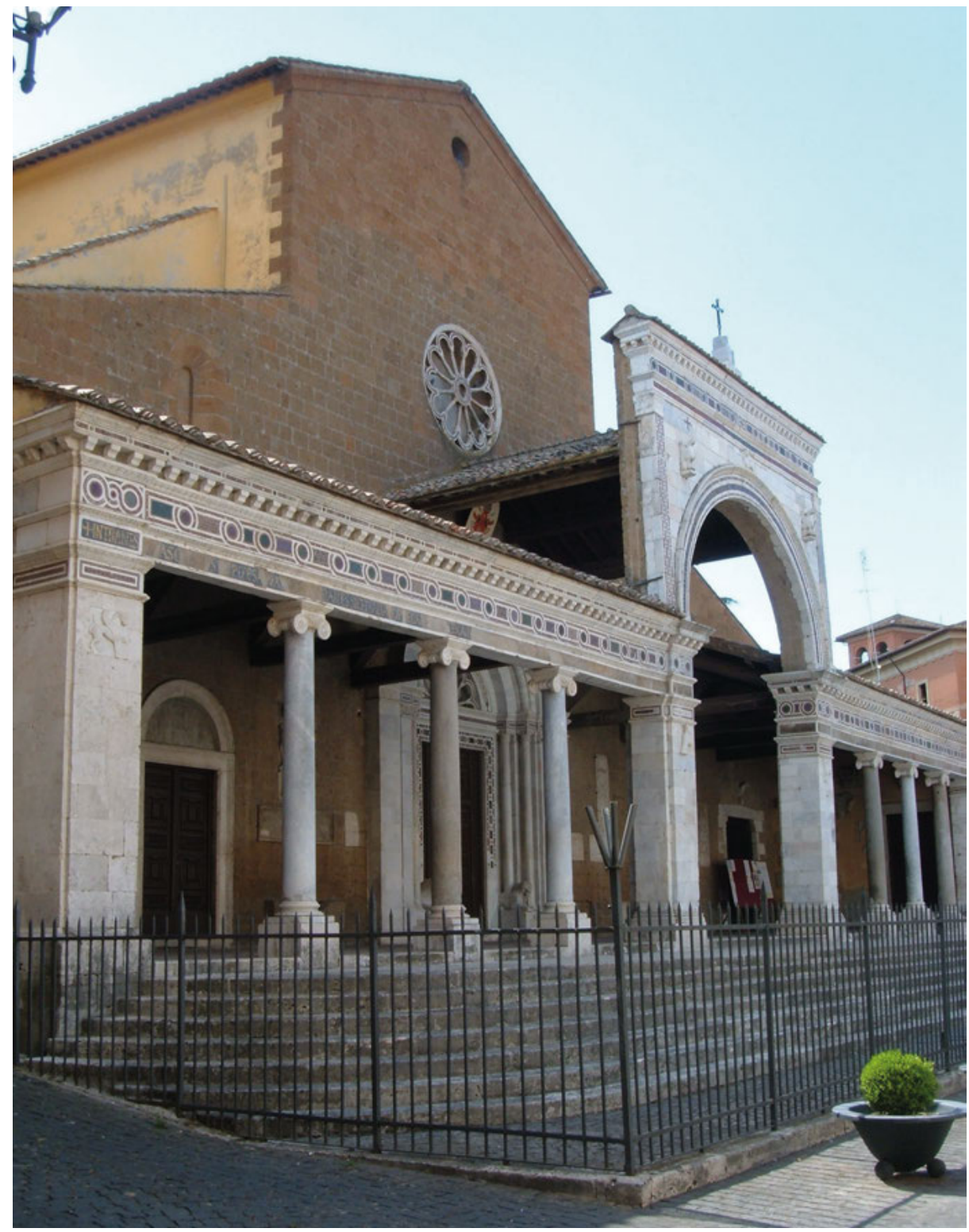

Abb.18: Civita Castellana, Duomo, Portikus vor der Westfassade.

ten mittleren Bogens (Abb.19) trägt auf dem Architrav in goldenen Mosaikbuchstaben die Künstlerinschrift mit der Datierung: ${ }^{39}$ + MAGISTER IACOBVS CIVIS ROMANVS CVM COSMA FILIO + SVO CARISIMO FECIT OHC OPVS ANNO D(omi)NI

39 Dietl 2009, 771. 


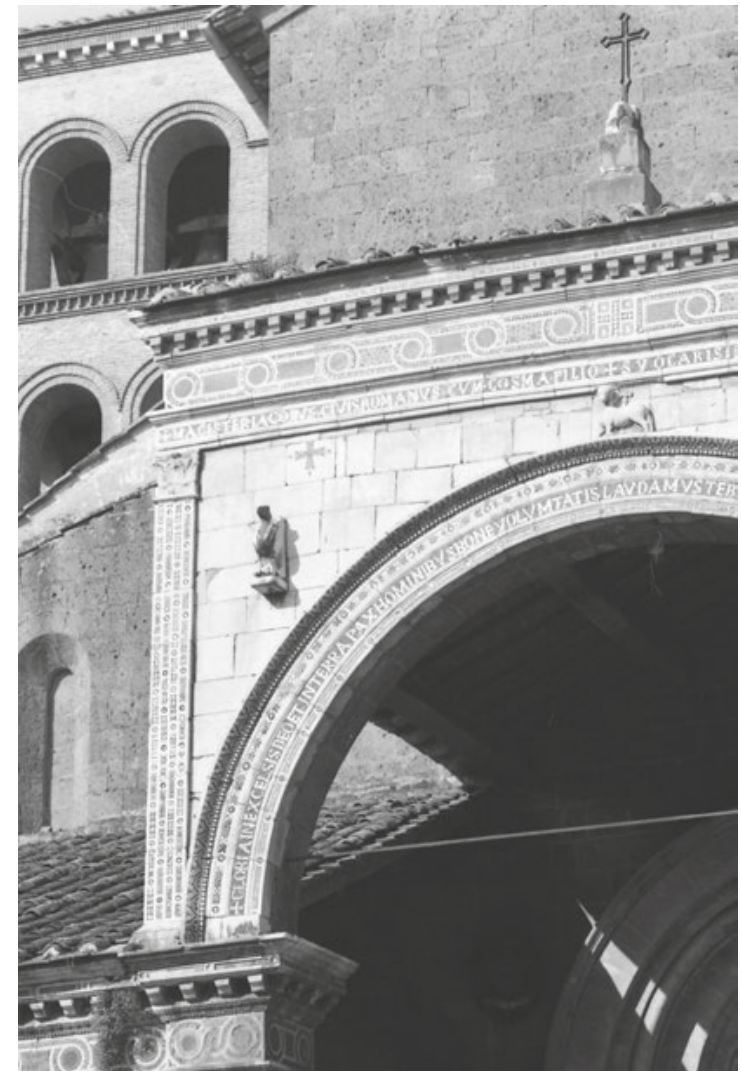

Abb.19: Civita Castellana, Duomo, Portikus vor der Westfassade, Inschrift auf dem Bogenlauf und dem Architrav des Mittelteils.

M C C X + (Der Meister Jacobus, Bürger von Rom, hat zusammen mit einem überaus geliebten Sohn Cosmas dieses Werk im Jahr des Herrn 1210 gefertigt). Das mittlere Kreuz bezeichnet die Mittelachse des Bogens und wiederholt das inkrustierte Kreuz im Fries darüber. Die architraviert gestaltete Bogenrahmung trägt in goldenen Kapitalisbuchstaben eine zweite, etwas größere Mosaikinschrift: + GLORIA IN EXCELSIS DEO ET IN TERRA PAX HOMINIBVS BONE VOLVMTATIS LAVDAMVS TE BENEDICAMVS TE ADORAMVS TE GLORIFICAMVS TE GRATIAS AGIMVS (Ehre sei Gott in der Höhe und auf Erden Friede den Menschen guten Willens; wir loben Dich, wir preisen Dich, wir beten Dich an, wir rühmen Dich, wir sagen Dir Dank). Dem Lobgesang der Engel (Lk 2,14) folgt das Gloria der Messe. Die architektonische Formel des Triumphbogens (Abb. 20) ist hier mit dem angemessenen christlichen Gloria-Deo-Text versehen. Das Gebälk der seitlichen Kolonnaden trug auf dem mosaizierten Architrav lange Inschriften, von denen nur geringe Teile erhalten und überliefert sind, die sich an die „Eintretenden“ (Intrantes) richteten. ${ }^{40}$

40 Claussen 1987, 85f. 


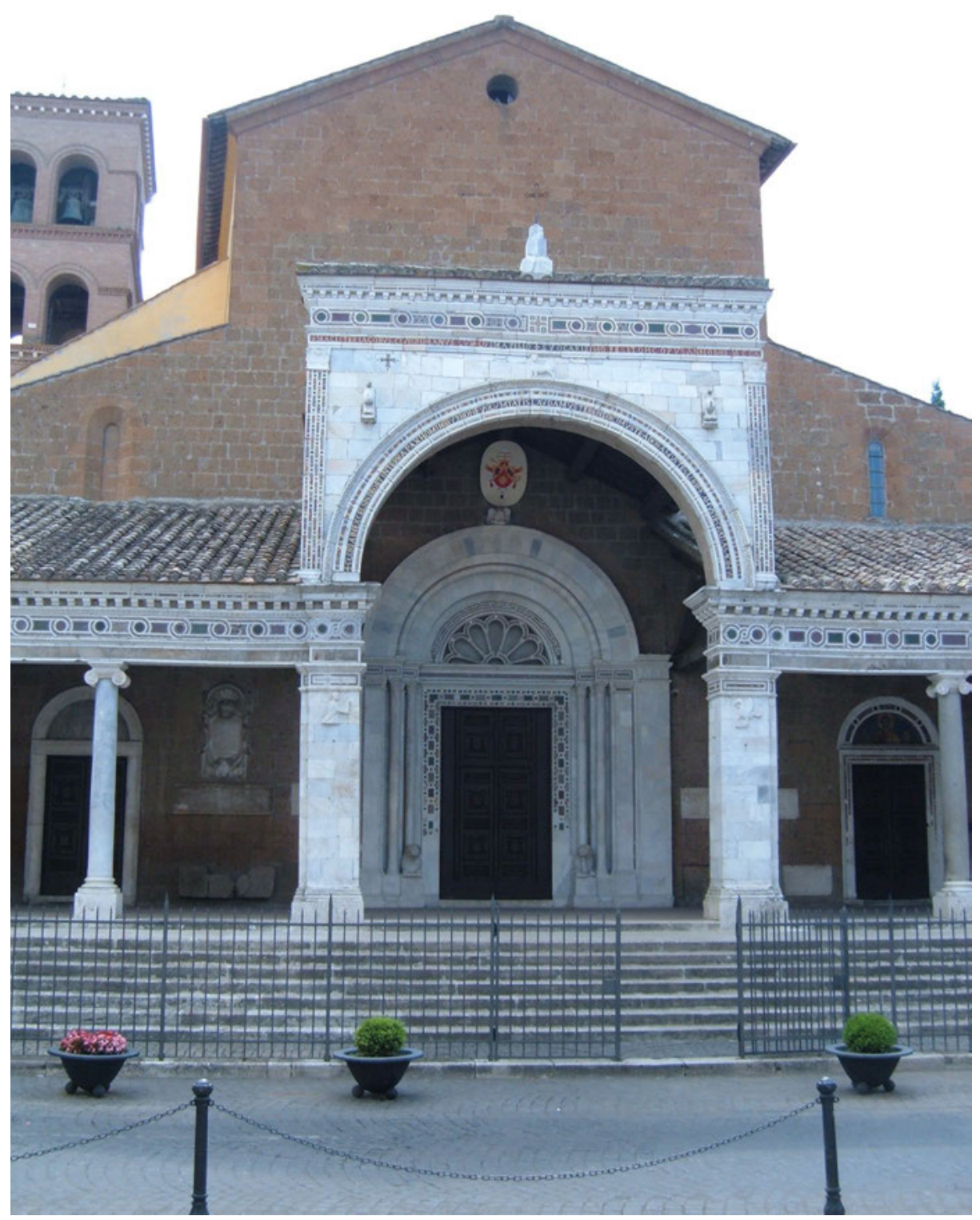

Abb. 20: Civita Castellana, Duomo, Portikus vor der Westfassade, Mittelteil.

Gestalterisch verwandt, aber ohne monumentale Wirkung sind die lang umlaufenden, mosaizierten Inschriften auf den Architraven der Kreuzgänge von S. Paolo fuori le mura (1205-1241) und S. Giovanni in Laterano (1215-1232) in Rom. 


\section{Kirchliche Fassadeninschriften der frühen Renaissance}

Die demonstrative Wiederaufnahme der Baugestalt römischer Tempelfassaden im 15. Jahrhundert durch italienische Humanisten gehört in den Beginn der Renaissance. Dem römischen Vorbild folgend, nennen die monumentalen Inschriften dieser neuen Kirchenfassaden den Stifter des Bauwerks, aber nun auch das Jahr. Den Beginn machen zwei Fassadenentwürfe von Giovanni Battista Alberti, jeweils im Auftrag reicher und mächtiger, aber nicht von Alters her etablierter Machthaber. ${ }^{41}$ Auf dem Fries unter dem Hauptgiebel der Westfassade der Dominikanerkirche Santa Maria Novella in Florenz steht in ca. $50 \mathrm{~cm}$ großen Kapitalis-Lettern (Abb. 21 und 22): IOHANES ORICELLARIVS PAV(li) F(ilius) AN(no) SAL(utis) MCCCCLXX (Iohannes oricellarius Pauli filius, Anno salutis MCCCLXX - Giovanni di Paolo Rucellai, im Jahr des Heils 1470). ${ }^{42}$ Die unvollendete Fassade der Franziskanerkirche („Tempio Malatestiano“) in Rimini trägt auf dem Fries der triumphbogenartigen Erdgeschosszone

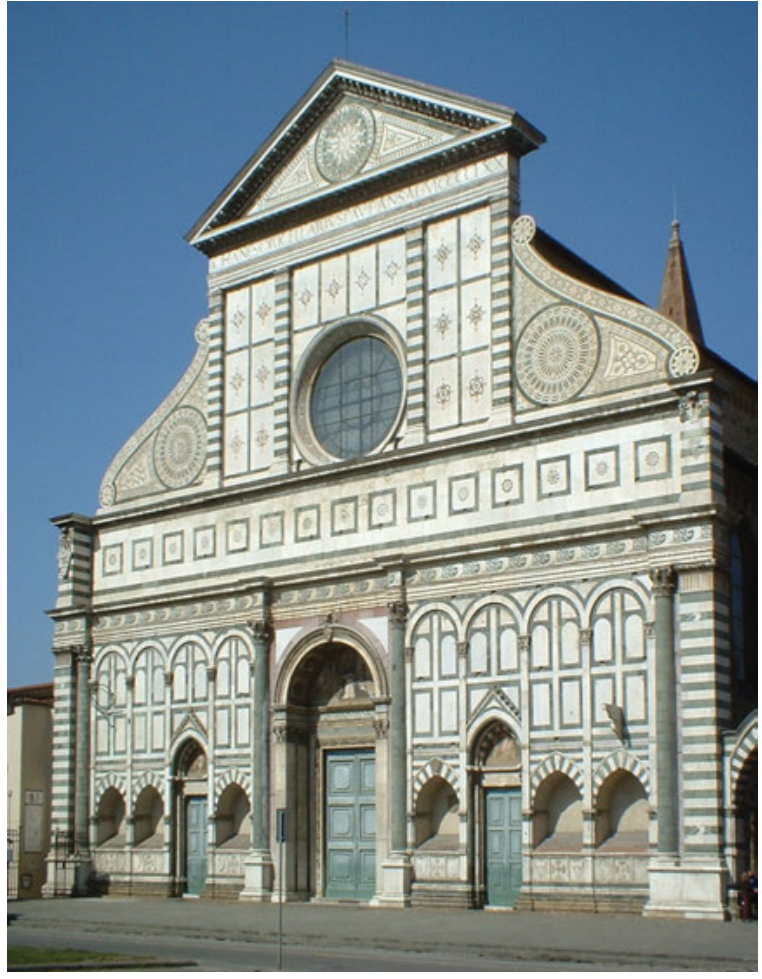

Abb. 21: Florenz, Dominikanerkirche Santa Maria Novella, Westfassade.

41 Mardersteig 1959.

42 Borsi 1982, 75-105; Hatfield 2004. 


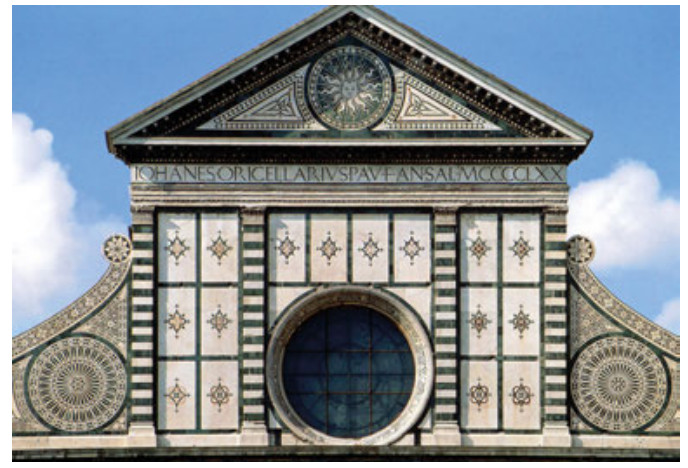

Abb. 22: Florenz, Dominikanerkirche Santa Maria Novella, Westfassade, Inschrift auf dem Fries.

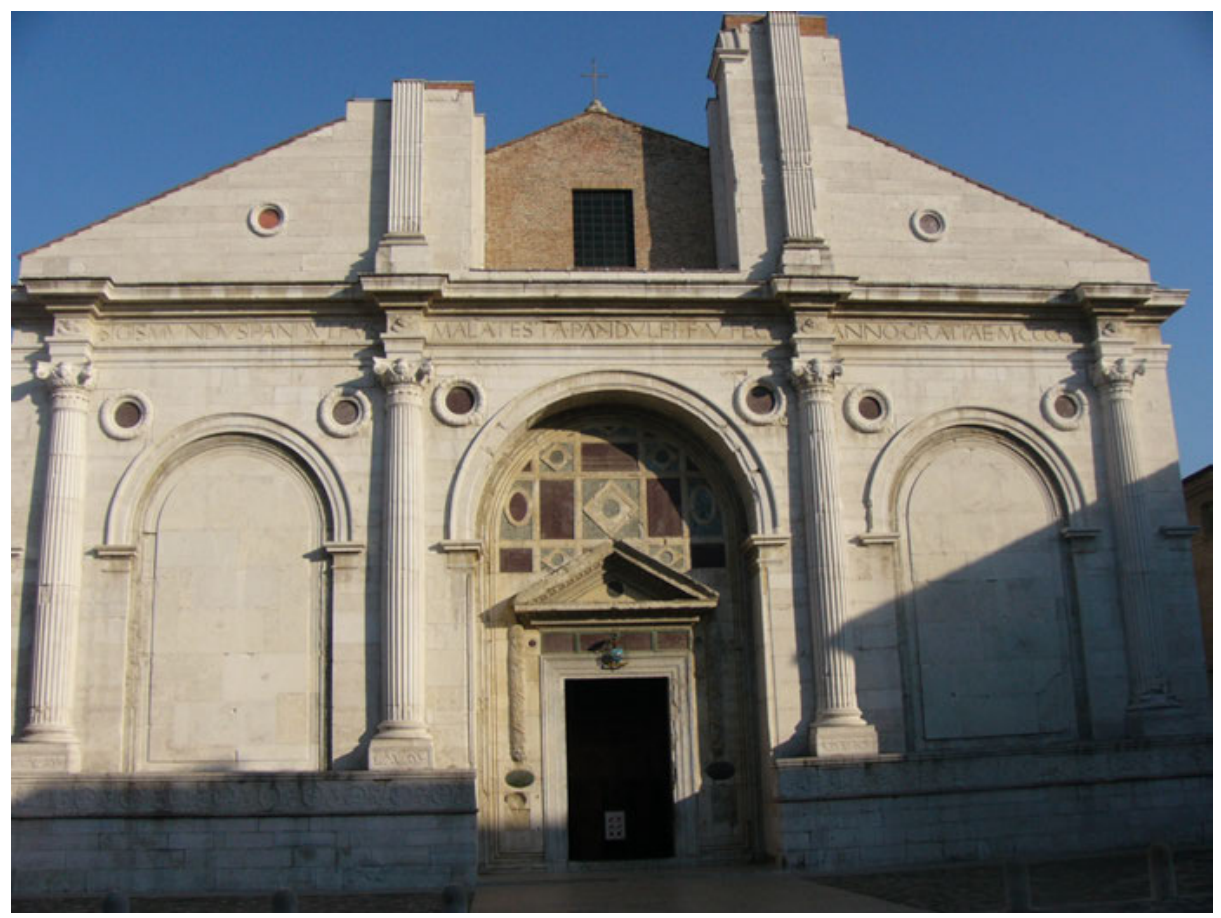

Abb. 23: Rimini, Franziskanerkirche (Tempio Malatestiano), unvollendete Westfassade.

eine ähnlich monumentale Inschrift, die Auftraggeber und Jahr des Baubeginns nennt (Abb.23): SIGISMVNDVS PANDVLFVS // MALATESTA PANDVLFI F(ilius) V(oto) FECIT // ANNO GRATIAE MCCCCL (Sigismondo Pandolfo Malatesta, Sohn des Pandolfo erbaute [die Kirche] aus seinem Gelübde im Jahr der Gnade 1450). ${ }^{43}$ Ausführlichere Informationen zur Stiftung bieten zwei zu Seiten des Portals ange-

43 Ricci 1924; Brandi 1956; Borsi 1982, 127-191. 
brachte Inschriften auf Marmortafeln, eine davon auf Griechisch. Die Polemik von Papst Pius II., dass diese Kirche ein „heidnischer Tempel“ zu sein scheine, bezieht sich nicht direkt auf die Baugestalt oder auf die Inschrift, sondern auf darin aufgestellte Kunstwerke (Aedificavit tamen nobile templum Arimini in honorem divi Francisci; verum ita gentilibus operibus implevit ut non tam Christianorum quam Infidelium daemones templum esse videretur). ${ }^{44}$ Die von Pius selbst in Auftrag gegebene Stiftskirche in Pienza erhielt keine Fassadeninschrift, sondern nur ein großes Wappenfeld.

\section{Monumentale Inschriften auf Kleinarchitekturen}

Als Kleinarchitekturen gestaltete Einbauten in Kirchen gab es seit dem frühen Mittelalter. Zwei zeichnen sich durch ihre großformatigen Inschriftbänder aus. Im Mittelschiff der Straßburger Bischofskirche stand ein 1316 erbauter, rechteckiger Altarbaldachin als Marienkapelle (Abb. 24). Er war rückseitig mit dem Lettner verbunden, zu dem der

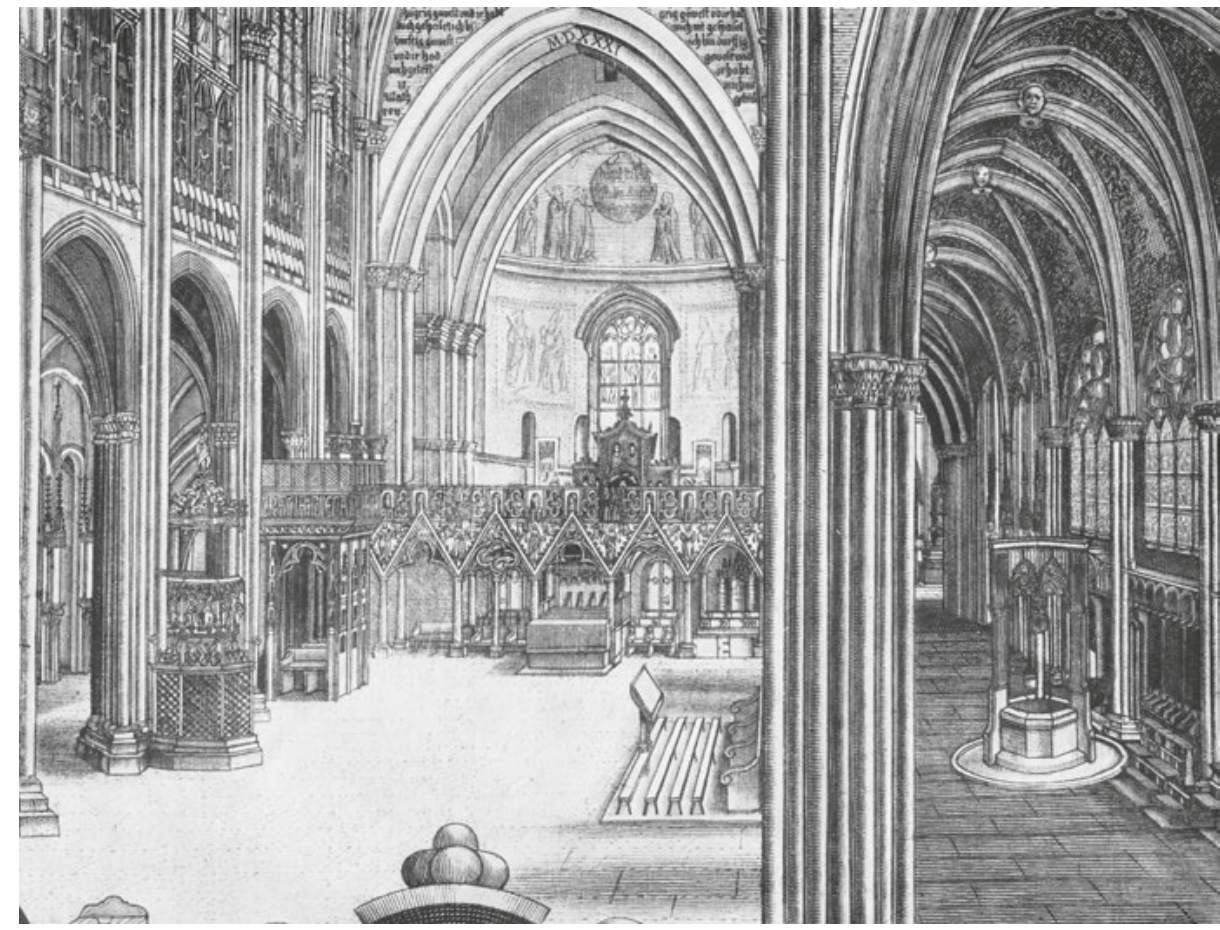

Abb. 24: Straßburg, Münster, Innenraum mit Marienkapelle; Isaac Brun, Kupferstich, 1630/31.

44 Piccolomini 1582, 92. 
Altar (sub ambone) und das wundertätige Marienbild bis 1316 gehört hatten. Der evangelische Geistliche und Gelehrte Daniel Schad notierte 1617: an der stehet im Geländer mit vberauss grossen an einander gehenckten alt fränckischen Versal Buchstaben das Ave Maria. Vber dem Geländer das Credo in Deum, etc. Vnd vnder demselben folgende Schrifft: M CCC XVI EDIFICAVIT HOC OPVS MAGISTER ERWIN. Ecce Ancilla Domini. Fiat mihi secundum verbum tuum. Amen. ${ }^{45}$ Die Situation um 1630 ist in einer Vedute von Isaac Brun überliefert. ${ }^{46}$ Einige Inschriftfragmente blieben nach dem Abbruch 1682 erhalten und befinden sich heute im Musée de l'Euvre Notre-Dame. ${ }^{47}$ Die Steinplatten waren wohl als vorkragende Traufplatten waagerecht auf die Mauerkrone der Kapelle aufgelegt. Sie tragen an ihrer Unterseite die überlieferte, umlaufende, mit erhabenen Lettern gearbeitete Inschrift (Abb. 25 und 26): [...]EDIFICAV(it) H(oc) OP(vs) MAG(iste)R ERWIN / EC[CE ... SECVNDV]M V[E]RBVM TV[VM] (Dieses Werk hat gebaut Meister Erwin / Siehe ... nach Deinem Wort). In bemerkenswerter Weise sind die Kürzungszeichen in den umlaufenden Wulst oberhalb der Inschrift eingraviert.

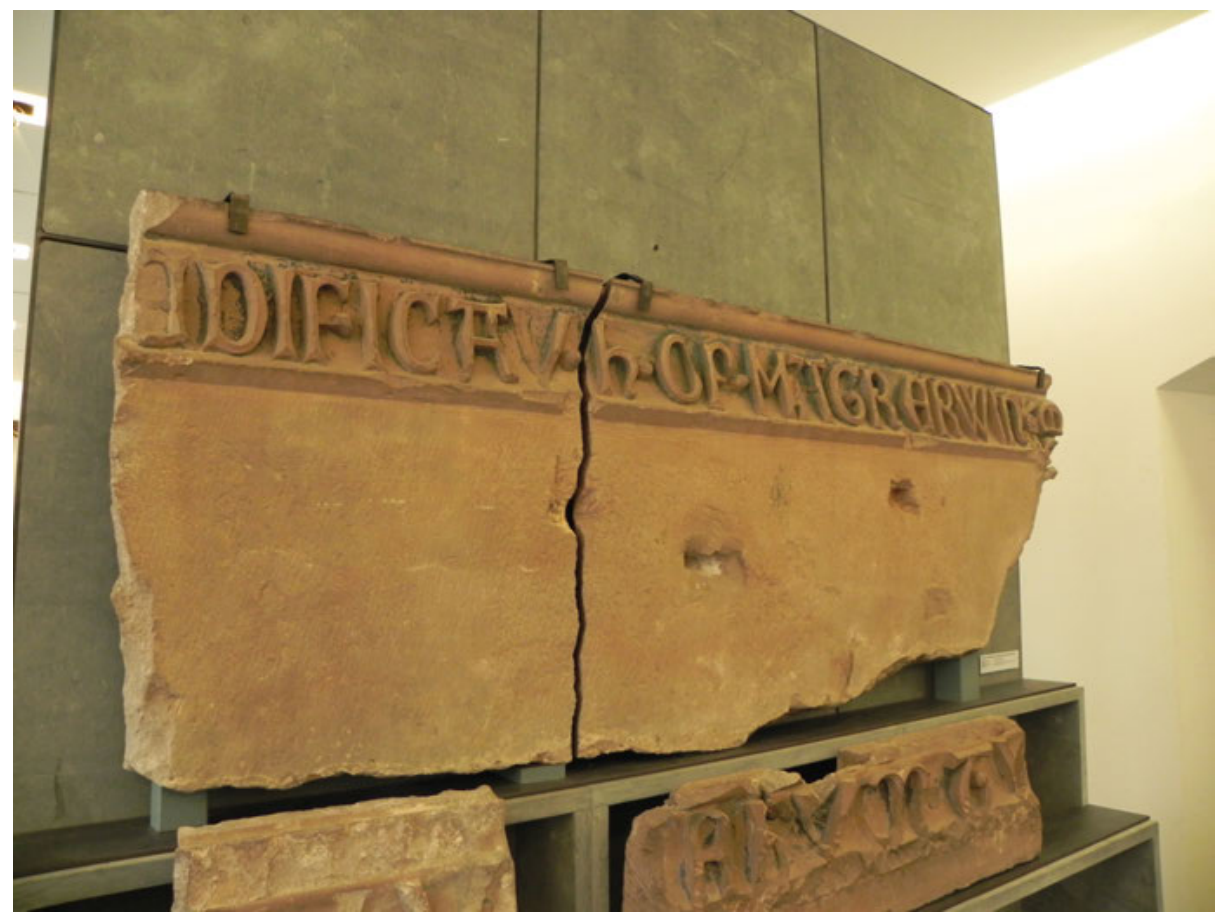

Abb. 25: Straßburg, Münster, Marienkapelle, Fragmente der Inschriften am Dachgesims.

45 Schad 1617, 68.

46 Walter 1935, 61-65, 103-106.

47 Liess/Köpke 1989, 122-125, 166 Q 46-49; Bayer 2011. 
Matthias Untermann
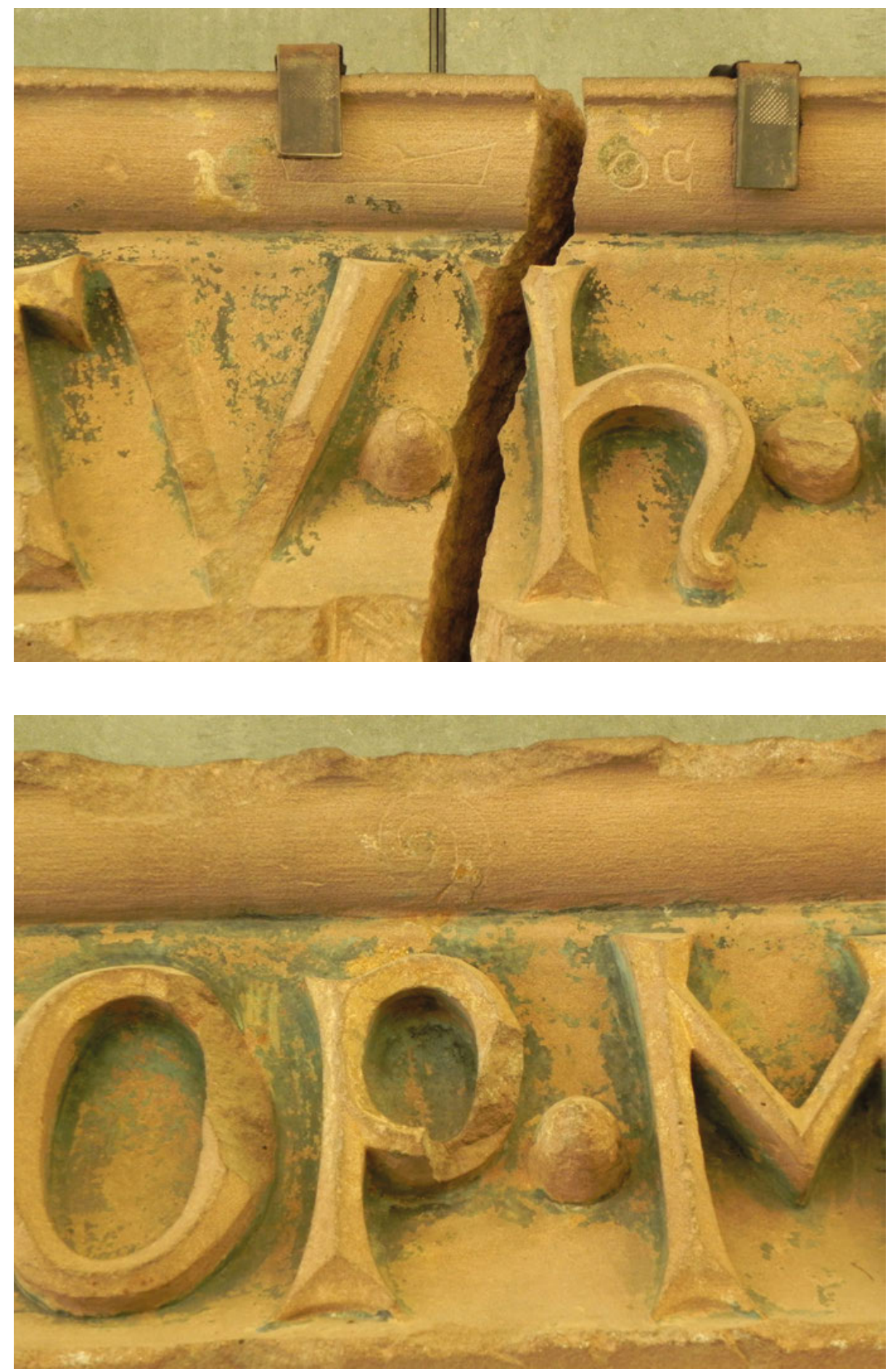


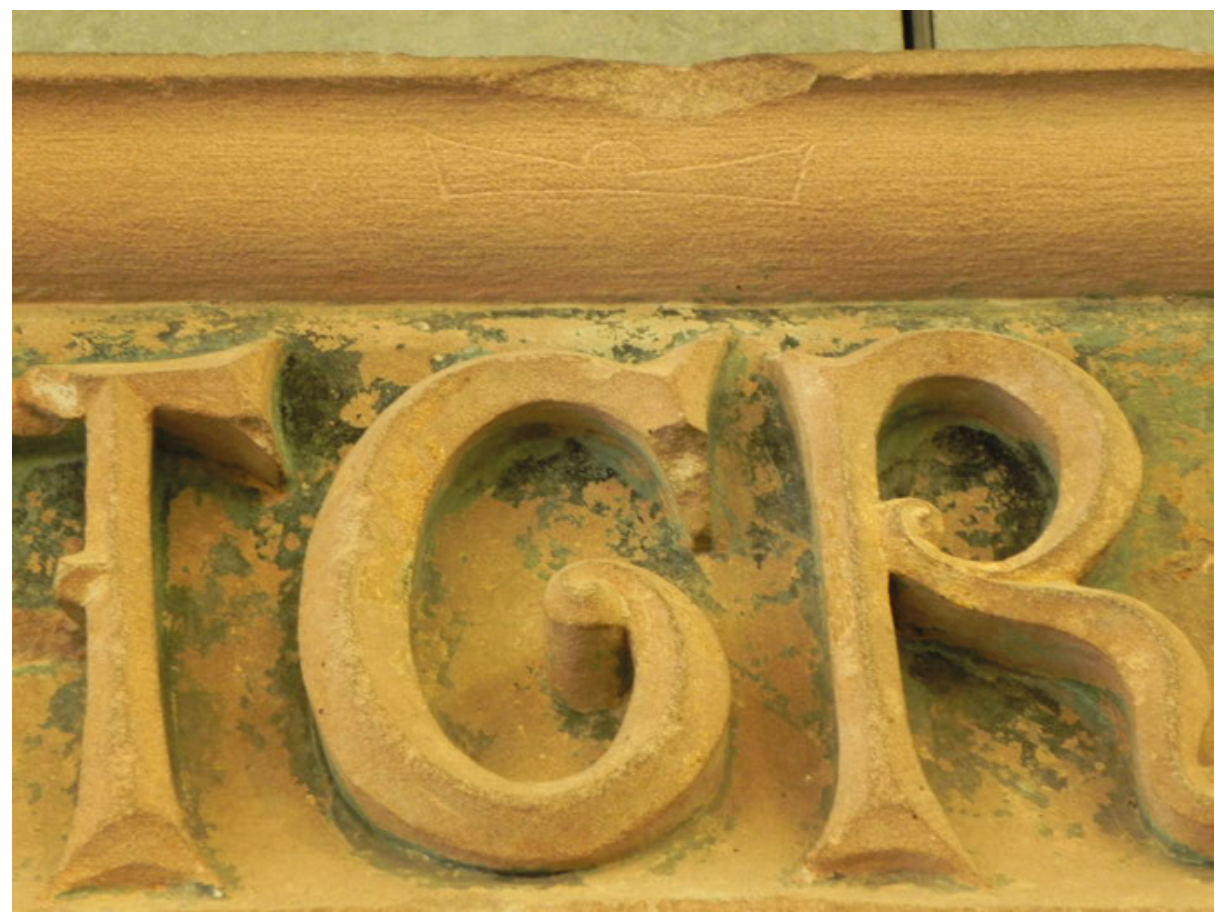

Abb. 26.1-3: Straßburg, Münster, Marienkapelle, Details der Inschriften am Dachgesims.

Einen Lageplan sowie einen Teil der großen Ave-Maria-Inschrift hat Johann Jacob Arhardt 1667 in Zeichnungen überliefert (Abb.27): D(omi)N(v)S TECV(m) BENED(i)C(t)A TV I(n) MVLIER(ibvs) (der Herr sei mit Dir, Du bist gebenedeit unter den Frauen). ${ }^{48}$ Dieser lange Text stand oben an der zum Mittelschiff hin gerichteten Südseite der Kapelle. Im Stich von 1630 ist ein Teil der Westfassade erkennbar: Die Anrede des Verkündigungsengels an Maria (Lk 1,28: Ave Maria gratia plena - Gegrüßest seist Du Maria, voll der Gnaden) stand über der schmalen westlichen Eingangsseite. Die Antwort der Maria (Lk1,38) Ecce ancilla Domini fiat mihi secuncum verbum tuum (Siehe, ich bin die Magd des Herrn, mir geschehe, wie Du gesagt hast) stand, wie die erhaltenen Fragmente zeigen, auf der Unterseite der Deckplatte, wohl ebenfalls beginnend über dem Eingang zur Kapelle. Anrede und Antwort liefen also parallel.

Raumwirksam war vornehmlich der große, wenn auch durch ornamentale Schrift nicht erst im 17. Jahrhundert schwer lesbare Text des „Ave Maria“. Nicht ein Weihetitel des Altars oder eine Bauinschrift, sondern eine religiöse Formel war hier präsent. Ihr Wortlaut war jedem mittelalterlichen Christen bekannt, musste also nicht ,gelesen“ werden. Das „Ave Maria“ wurde in dieser Bischofskirche, vermutlich auch an der Kapelle selbst, regelmäßig, ohne weitere Aufforderung, vielhundertfach rezitiert.

48 Liess 1985/86, 87-89, Abb. 14. 


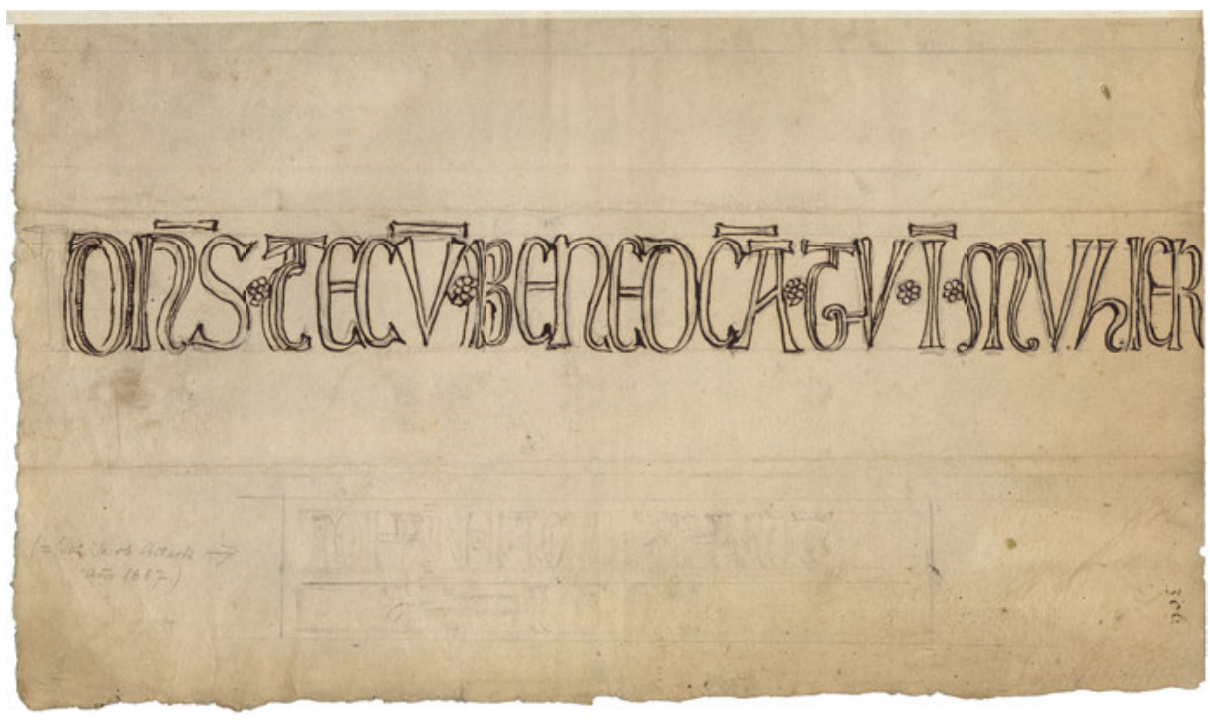

Abb. 27: Straßburg, Münster, Marienkapelle, Abzeichnung der Inschrift; Johann Jacob Arhardt 1667, Staats- und Universitätsbibliothek Göttingen, Cod. Ms. Uffenbach 1, fol. 306.

Außen an diesem Gebäude, das im Inneren ein Bild der Muttergottes Maria beherbergte, wird die huldigende Ansprache des Verkündigungsengels im Raum in vornehmer Weise sichtbar gemacht, der sich die Gläubigen durch Rezitation anschließen. Die Verwendung von Text anstelle der auch in Domkirchen allgegenwärtigen bildlichen Darstellung der Verkündigung ist ungewöhnlich.

In welcher Weise das von Schad für die Brüstung überlieferte Credo inschriftlich gefasst war, ist vorerst unbekannt. In der primären Konzeption der Kapelle und ihrer Inschriften findet es keinen sinnvollen Platz - möglicherweise war es eine Zufügung der Reformationszeit, als die Bühne über der Kapelle nun regelmäßig von Adligen und Patriziern genutzt wurde, die dort am Gottesdienst teilnahmen.

Dem gleichen Kontext gehört die Kleinarchitektur des Heiligen Grabs an, das in grundsätzlich konventioneller Weise in einem Anraum der Klosterkirche San Pancrazio in Florenz steht (Abb.28). Es war, wie die (ebenfalls konventionelle) Inschrifttafel über der Tür überliefert, eine Stiftung des Patriziers Giovanni di Paolo Rucellai im Jahr 1467, der drei Jahre später die schon genannte Fassade von Santa Maria Novella stiftete. Als rechteckiger Baukörper mit einer Apsis und einer seitlich verschobenen Tür bildet das Monument den Grabbau Christi in der Jerusalemer Grabeskirche nach, mit dem leeren Grab als Glaubensbeweis der Auferstehung. ${ }^{49}$ Die reiche, inkrustierte Marmordekoration nach Entwurf von Leon Battista Alberti gehört zu den frühen 


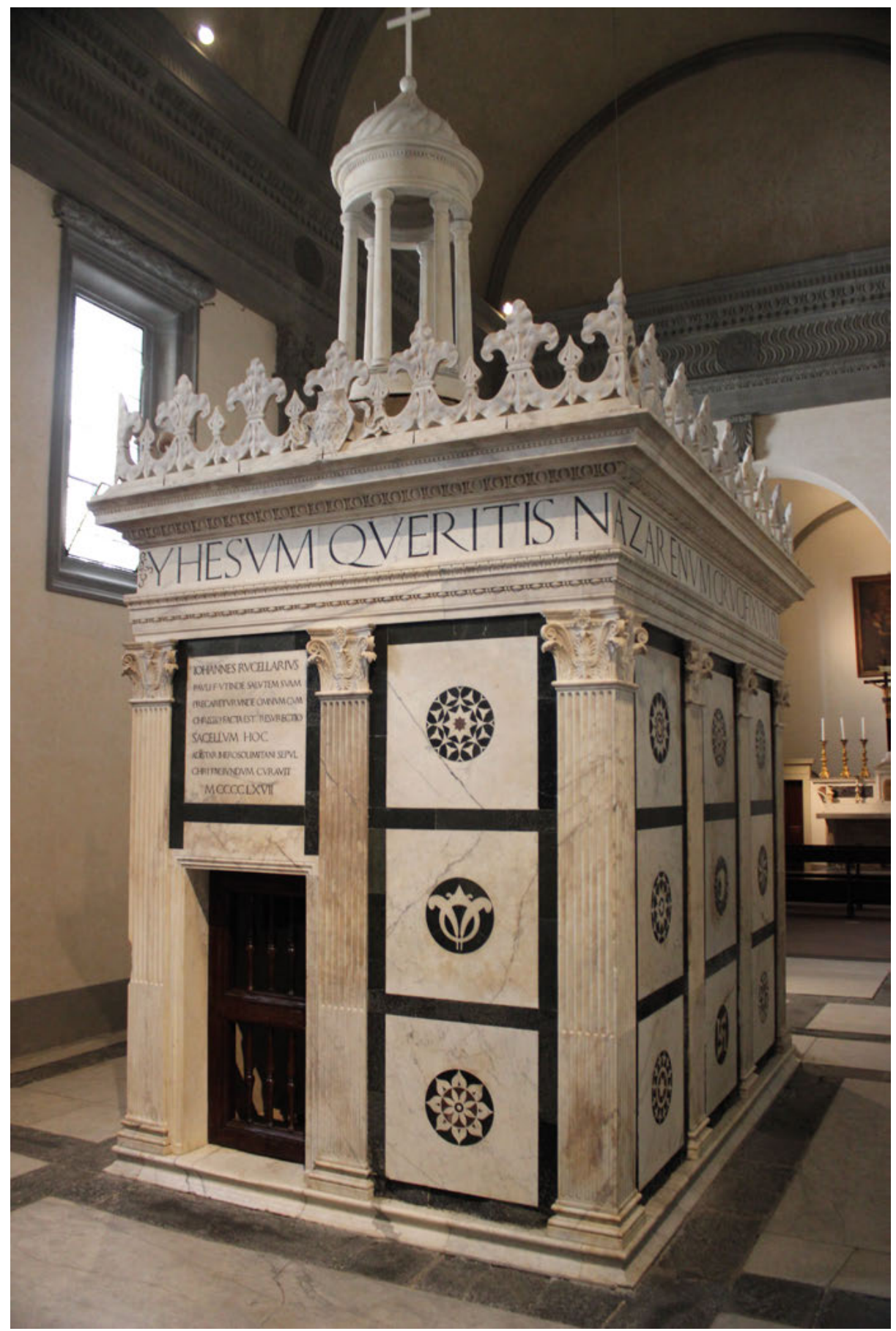

Abb. 28: Florenz, San Pancrazio, Capella Ruccellai, Fassade. 
Hauptwerken der Florentiner Renaissance..$^{50}$ Die Gestaltung und auch die Größe der Buchstaben folgt - wie an Santa Maria Novella - antik-römischen Vorbildern. ${ }^{51}$ Auf dem Fries des von korinthisierenden Pilastern getragenen Gebälks steht in $17 \mathrm{~cm}$ hohen Kapitalislettern umlaufend jener Vers aus dem Markusevangelium, den nach der Auferstehung Christi der Engel zu den drei zum Grab kommenden Frauen sprach (Mk 16,6): YHESVM QVERITIS N/AZARENVM CRVCIFIXVM SVR/REXIT NON EST HIC ECCE L/OCVS VBI POSVERVNT EVM (Ihr sucht Jesus, den gekreuzigten Nazarener, er ist auferstanden, er ist nicht hier, siehe, der Ort, wohin sie ihn gelegt hatten). Der Text wurde mit großer Überlegung layoutet: Über dem Eingang steht, an die Besucher gerichtet, YHESVM QVERITIS - Ihr sucht Jesus. Auf der Apsis, die zum Altar der Kapelle weist, ist die Auferstehungsbotschaft zu lesen (Abb.29): NON EST HIC - Er ist nicht hier. Nicht nur mit der der Frage über dem Eingang, sondern auch mit dem Hinweis ECCE LOCVS (Siehe, der Ort) spricht der Text unmittelbar den aktuellen Besucher an und fordert ihn auf, in Nachfolge der drei Frauen - letztlich also ersatzweise für eine Pilgerfahrt nach Jerusalem - das leere Grab wahrzunehmen und an die Auferstehung zu glauben. Der Text bezeichnet also das gebaute Monument, der - abwesende - Engel spricht ihn, und er gibt dem Besucher eine Handlungs- und Wahrnehmungsanweisung. Die Verwendung der Kapitalislettern betont die allgemeine Lesbarkeit und gibt dem Text zugleich - wie schon im Frühmittelalter - eine besondere, in vergangener Zeit fundierte Autorität. ${ }^{52}$

Alberti behandelte in seiner 1512 gedruckten theoretischen Schrift, den „Libri de re aedificatoria decem“, Inschriften nur knapp im Zusammenhang mit Triumphbögen. ${ }^{53}$ Schon Vitruv erwähnte Inschriften an Bauten gar nicht. Die von Alberti sorgfältig entworfenen Schriften belegen die hohe Bedeutung des formalen Entwurfs, ebenso wie die Einbindung des Heiligen Grabs in das zeitgleich gebaute Schiff der Kapelle. Festlegung des Textes und Layout der Inschrift dürften nicht Alberti, sondern einem anderen Berater oder Baubeteiligten zuzurechnen sein.

\section{Fassadeninschriften und sakrale Schrifträume}

Für die Kleinarchitekturen des 14./15. Jahrhunderts in Straßburg und Florenz lässt sich gut beschreiben, wie die Texte nicht nur einen ,sakralen Schriftraum definieren, sondern auch unmittelbar mit den Nutzern dieses Raums interagieren. Überraschenderweise fügt sich der frühe „Tempietto del Clitunno“ in diese Gruppe ein. Er ist zwar wegen seiner Hanglage nicht einfach zu umschreiten, präsentiert aber in gleicher

50 Borsi 1982, 105-125.

51 Mardersteig 1959; Tavernor 1994.

52 Krüger 2014.

53 Alberti 1512, lib. VIII, cap. 6, fol.126'-127'. 


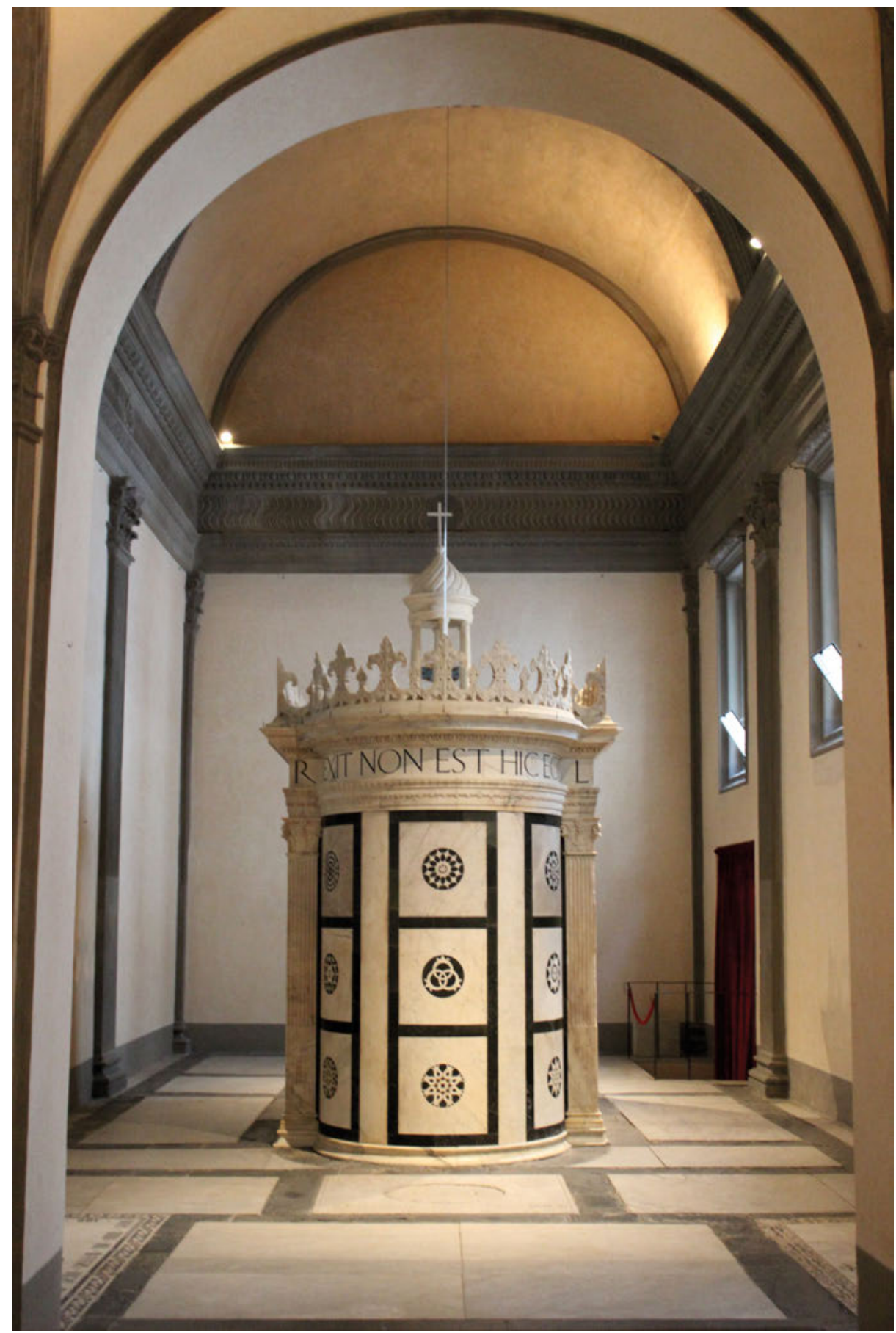

Abb. 29: Florenz, San Pancrazio, Capella Ruccellai, Apsis. 
Weise Glaubensbotschaften. Es bleibt zu fragen, ob diese Botschaften die Funktion des Gebäudes nach außen tragen oder ob nicht gerade die Tempelfronten diesen Aussagen Autorität verleihen. Der Tempietto wäre damit eher ein liturgisches Objekt als ein Bauwerk, das betreten werden sollte. Die dreiseitigen Fassaden machen deutlich, dass ein ausreichend großer Sakralbezirk zu diesem Monument gehört haben muss. Da der Innenraum nur die Größe eines Altarraums hat, war er sicher nicht Ort öffentlicher Gottesdienste - allenfalls dann, wenn das Kirchenvolk außerhalb des Gebäudes stand. Das Tempelmotiv würde damit nicht auf reale antike Tempel Bezug nehmen, sondern auf die längst üblichen Tempelmotive an Schrankenanlagen und in liturgischen Buchillustrationen. ${ }^{54}$ Wie eine monumentale Chorschranke - mit integriertem Triumphbogen - gestaltet ist auch die Vorhalle des Doms von Civita Castellana: Auch hier ist also vor der Kirchenfassade ein sakraler, wenn auch nicht überdachter Raum imaginiert. Ob dies der architektonischen Situation und einer liturgischen Praxis des 13. Jahrhunderts entsprach oder eher eine (ohne unmittelbare Nachfolge bleibende) formale Gestaltungsidee war, die mit theologischer Bildung hinterlegt ist, bleibt zu fragen. Die Deutung dieses Triumphbogens als Ziel der Via Flaminia und „architektonisches Zeichen des päpstlichen Friedensreiches ${ }^{* 55}$ wird den Texten der Inschrift kaum gerecht, auch wenn die Gestaltung dieser Vorhalle in der Frührenaissance selbst zum Vorbild wurde. ${ }^{56}$

Die zweite Gruppe der Fassadeninschriften öffnet den Blick auf einen anderen Aspekt des sakralen Schriftraums. Sakrale Stätten sind in der Antike wie im christlichen Mittelalter nur in besonderen Fällen aus sich heraus bedeutsam. Tempel wie Kirchen bedürfen eines Stifters, der die Initiative zum Bau hat und diesen finanziert und organisiert. Dass das Verhältnis zwischen Stifter und Tempel auch in der Antike schwierig sein konnte, zeigt die Inschrift des Pantheon. In der christlichen Praxis war es - wie die wenigen Beispiele ex negativo belegen - nicht untersagt, aber durchaus unüblich, seinen Namen groß an der Kirchenfassade anzuschreiben. ${ }^{57}$ Die Inschrift in San Vincenzo al Volturno wird deshalb als Indiz für die Rezeption und Nachbildung antiker Praktiken gewertet - in einem Kontext mit der Verwendung antiken Baumaterials und anderer Elemente einer „karolingischen Renaissance“. ${ }^{8}$ Für die Kirchenfassaden des 15. Jahrhunderts ist dieser Zusammenhang unstrittig, auch wenn die Textformeln selbst keine unmittelbare Wiederholung antiker Stifterinschriften darstellen, sondern in mittelalterlicher Tradition stehen. ${ }^{59}$ Die mittelalterlichen Fassadeninschriften sind jedoch mehr als eine formale Nachbildung antiker

54 Zu Kanontafeln: Réfice 1993.

55 Claussen 1987, 88; nach Noehles 1966, 30 f.

56 Bertelli 1956; Claussen 1987, 90f.; Portoghesi 2012.

57 Allgemein zu Portalinschriften: Kendall 1998.

58 Mitchell 1994, 918. Zu entsprechenden Deutungen des „Triumphbogens“ in Civita Castellana: Claussen 2012.

59 Dietl 2009. 
Stifterinschriften - als solche wären sie wenig gelungen, und der „Tempietto“ wie die Bauten des 15. Jahrhunderts zeigen, dass eine formal präzise Übernahme ohne Mühe konzipiert werden konnte. In San Vincenzo wird der Ruhm dezidiert dem Abt und dem Konvent zugewiesen, in Salerno der kriegerische Triumph des Stifters betont, in Foligno die schwierigen Zeitumstände hervorgehoben. Dies ging jeweils über die angemessenen Formeln des Stiftergedächtnisses hinaus, weil es dezidiert Ereignisse und Statusfragen ,außerhalb“ des Kirchenraums auf diese Gebäude bezog. In San Vincenzo ist die architektonische, organisatorische und herrschaftliche Struktur der sehr ungewöhnlichen, komplexen Klosteranlage für Besucher im 9. Jahrhundert (und noch für die heutige Forschung) kaum zu durchschauen. ${ }^{60}$ Es gab mindestens zehn Kirchen und Kapellen; der monastische Baukomplex erstreckte sich über ein großes Gebiet und beherbergte ganz unterschiedliche klösterliche Gruppen, wohl mit unterschiedlichen Aufgaben und vielleicht auch unterschiedlicher Organisation. Dass Abt und Konvent in San Vincenzo gemeinsam eine große Kirche errichten und ausstatten ließen, ist für solche Großkonvente der Karolingerzeit keineswegs selbstverständlich. Nicht nur die Verleihung der Abtswürde (und der damit verbundenen Herrschaftsrechte und Einkünfte) durch den König, sondern auch die erheblichen sozialen, finanziellen und geistlichen Differenzen zwischen den verschiedenen Gruppen der Mönchsgemeinschaft führten vielerorts zu heftigen Auseinandersetzungen, wie es in Saint-Denis, Fulda oder St. Gallen gut belegt ist ${ }^{61}$ - oft auch mit negativen Auswirkungen auf Baumaßnahmen.

In Salerno, Foligno und Bovara sind die herrschaftlichen und sozialen Spannungen im Wortlaut der Inschriften leichter zu greifen. Die triumphale Eroberung der Stadt Rom durch Herzog Robert und die Flucht Papst Gregors VII. nach Salerno gehörten zu den dramatischsten Ereignissen des frühen Investiturstreits. Aber auch der aufwändige Kathedralbau in Foligno zur Zeit einer großen Hungersnot dürfte den städtischen Frieden schwer belastet haben. Die Inschriften geben dem in beiden Fällen letztlich friedlichen Ausgang dieser Krisen eine dauerhafte Erinnerung, die in Foligno durchaus gegensätzliche Gruppen der Stadt - Klerus, Stadtregierung, Volk demonstrativ integrierte. Die große Inschrift Attos in Bovara zeigt, dass das Verhältnis zwischen diesem Werkmeister und dem Konvent der Benediktinerabtei kein gewöhnliches gewesen sein kann - nimmt man den Text wörtlich, ist es die monumentalste Handwerkerinschrift, die wir aus dem Mittelalter kennen. ${ }^{62}$ Atto war vielleicht der „Baumeister und Bürgermeister“, an den in der eben genannten Inschrift im nahen Foligno erinnert wurde. Da die Geschichte der Abtei Bovara noch kaum erforscht ist, bleibt der Anlass für diesen Text vorerst unbekannt.

60 Marazzi 2014.

61 Semmler 1989, 78-111; Untermann 2006, 133-139.

62 Dietl 2009, 675-677. Zur ebenso bemerkenswerten, zeitweisen Anonymität der gotischen Kathedralbaumeister: Claussen 1993/94; Claussen 2008. 
Selbstverständlich geht es auch bei solchen Bezügen auf Herrschaft und Hungersnöte letztlich um „Sakralität“: Die Realisierung eines Kirchengebäudes war für alle Beteiligten eine hochrangige Aufgabe in ihrer eigenen religiösen Praxis und ihrem religiösen Selbstverständnis, und die Einschreibung des Namens sicherte weit über „Memoria“ hinaus als rechtlich verstandene, für das Seelenheil relevante Ansprüche. ${ }^{63}$

Die Friesinschriften des 8. bis 15. Jahrhunderts gehen jedoch über diese konventionelle Praxis hinaus: Sichtbarkeit von Außen und demonstrative Botschaft nach Außen waren konstitutiv für diese Inschriften, nicht Selbstvergewisserung der innerhalb der Kirche schon versammelten elitären christlichen Gemeinschaft und ihrer Liturgie. Ort und Inhalt der Texte überschreiten eine Grenze.

Fassadeninschriften gab es offenbar nur in recht geringer Zahl, jedesmal aber in besonderen historischen Kontexten. Nur selten war es offenbar notwendig, den sakralen Schriftraum des mittelalterlichen Kirchengebäudes in dieser Weise nach Außen zu erweitern. Nicht die „Antikenimitation“ dürfte deshalb primäre Absicht der Konzepteure und Auftraggeber dieser monumentalen Inschriften gewesen sein, sondern aktuelle, mit traditionelleren Mitteln nicht lösbar erscheinende Kommunikationsbedürfnisse im Grenzbereich zwischen „Kirche und Welt““.

\section{Literaturverzeichnis}

Alberti, Leon Battista (1512), Libri de re aedificatoria decem, Paris.

Amy, Robert/ Gros, Pierre (1979), La maison carrée de Nîmes, 2 Bde., Paris.

Andaloro, Maria (1985), „Ancora volta sull'Ytalia di Cimabue“, in: Arte medievale 2, 1984 (1985), 143-177.

André, Pierre/Chalon, Marc (2012), „Le Temple du Forum De Vienne etait consacré a Jupiter et non a Auguste et encore moins a Livie“, in: Le Chroniqueur, 10. Februar 2012, <http://www. lechroniqueur.fr/fr2/dossiers/cat.php?val=65_patrimoine> (Stand 30.1.2018).

Bayer, Clemens M. M. (1999), „Die karolingische Bauinschrift des Aachener Domes“ in: Max Kerner (Hg.), Der verschleierte Karl. Karl der Große zwischen Mythos und Wirklichkeit, Aachen, 445-452.

Bayer, Marion (2011), „Inschrift der Marienkapelle des Straßburger Münsters mit Nennung des Baumeisters Erwin von Steinbach“, in: Der Naumburger Meister. Bildhauer und Architekt im Europa der Kathedralen, Bd. 1 (Katalog zur Landesausstellung in Sachsen-Anhalt, 2011), hg. v. Hartmut Krohm u. Holger Kunde, Petersberg, 114-116, Nr. I.9.

Bertelli, Carlo (1956), „La capella dei Pazzi e Civita Castellana“, in: Paragone Arte 7, 57-63.

Binazzi, Gianfranco (Hg.) (1989), Regio VI, Umbria (Inscriptiones Christianae Italiae 6), Bari.

Borsi, Franco (1982), Leon Battista Alberti. Das Gesamtwerk, Stuttgart.

Brandenburg, Hugo (2004), Die frühchristlichen Kirchen Roms vom 4. bis zum 7. Jahrhundert. Der Beginn der abendländischen Kirchenbaukunst, Regensburg.

Brandi, Cesare (1956), Il Tempio Malatestiano, Turin.

63 Zettler 2001. 
Buddensieg, Tilman (1971), „Criticism and praise of the Pantheon in the Middle Ages and the Renaissance“, in: R. R. Bolgar (Hg.), Classical influences on European culture A. D. 500-1500 (Proceedings of an International Conference held at King's College, Cambridge, April 1969), Cambridge, 259-267.

Calabi Limentani, Ida (1970), ,,Sul non saper leggere le epigrafi classiche nei secoli XII et XIII. Sulla scoperta graduale delle abbreviazioni epigrafiche. 'A proposito di un libro recente“, in: Acme 23, 253-282; wiederabgedruckt in: Ida Calabi Limentani (2010), Scienza epigrafica. Contributi alla storia degli studi di epigrafia latina (Epigrafia e antichità 28), Faenza, 11-42.

Corpus Inscriptionum Latinarum.

Claussen, Peter Cornelius (1987), Magistri doctissimi Romani: Die römischen Marmorkünstler des Mittelalters (Corpus Cosmatorum 1; Forschungen zur Kunstgeschichte und christlichen Archäologie 14), Stuttgart.

Claussen, Peter Cornelius (1993/94), „Kathedralgotik und Anonymität 1130-1250“, in: Wiener Jahrbuch für Kunstgeschichte 46/47, 141-161.

Claussen, Peter Cornelius (2008), „L'anonimato dell'artista gotico. La realtà di un mito“, in: Maria Monica Donato (Hg.), L'artista medievale (Annali della Scuola normale superiore di Pisa, ser. IV, Quaderni 16, 2003), Pisa, 283-297.

Claussen, Peter Cornelius (2012), „Perchè non tante facciate come quella di Civita Castellana? Identità e rivalità - periferia e centro“, in: Luca Creti (Hg.), La cattedrale cosmatesca di Civita Castellana (Atti del convegno internazionale di studi, Civita Castellana, 18-19 settembre 2010), Rom, 233-242.

Clemens, Lukas (2003), Tempore Romanorum constructa. Zur Nutzung und Wahrnehmung antiker Überreste nördlich der Alpen während des Mittelalters (Monographien zur Geschichte des Mittelalters 50), Stuttgart.

Coüasnon, Charles (1974), The church of the Holy Sepulchre in Jerusalem (The Schweich lectures of The British Academy, 1972), London.

Dietl, Albert (2009), Die Sprache der Signatur (Italienische Forschungen des Kunsthistorischen Institutes in Florenz, Max-Planck-Institut Folge 4, 6), Berlin / München.

Emerick, Judson J. (1992), The Tempietto del Clitunno near Spoleto, University Park (Pa).

Eroli, Giovanni (1895), Raccolta generale delle iscrizioni pagane e cristiane esistite ad esistenti nel Pantheon die Roma, Narni.

Federici, Vincenzo (Hg.) (1925-1928), Chronicon Volturnense, 3 Bde. (Fonti per la storia d'Italia 58-60), Rom.

Formigé, Jules (1924), „L'inscription du temple de Rome et d'Auguste à Vienne“, in: Comptes rendus des séances de l'Académie des Inscriptions et Belles-Lettres 4, 275-279.

Giersiepen, Helga (1991), Die Inschriften des Aachener Doms (Die deutschen Inschriften 31), Wiesbaden.

Hatfield, Rab (2004), „The Funding of the Façade of Santa Maria Novella“, in: Journal of the Warburg and Courtauld Institutes 67, 81-128.

Hodges, Richard (1996), The basilica of Abbot Joshua at San Vincenzo al Volturno (Miscellanea vulturnense 2), Monteroduni.

Jäggi, Carola (1998), San Salvatore in Spoleto. Studien zur spätantiken und frühmittelalterlichen Architektur Italiens (Spätantike, frühes Christentum, Byzanz, Reihe B: Studien und Perspektiven 4), Wiesbaden.

Kendall, Calvin B. (1998), The allegory of the church. Romanesque portals and their inscriptions, Toronto/Buffalo/London.

Kluge, Bernd (1999), „Nomen imperatoris und Christiana Religio. Das Kaisertum Karls des Großen und Ludwigs des Frommen im Licht der numismatischen Quellen“, in: 799. Kunst und Kultur der Karolingerzeit. Karl der Große und Leo III. in Paderborn, Bd. 3 (Beiträge zum Katalog der Ausstellung in Paderborn, 1999), hg. v. Christoph Stiegemann u. Matthias Wemhoff, Mainz, 82-90. 
Krüger, Jürgen (2000), Die Grabeskirche zu Jerusalem. Geschichte, Gestalt, Bedeutung, Regensburg. Krüger, Kristina (2014), „Nicht verborgen, sondern goldgehöht - doch nur den Wenigsten verständlich“, in: Tobias Frese, Wilfried E. Keil u. Kristina Krüger (Hgg.), Verborgen, unsichtbar, unlesbar - zur Problematik restringierter Schriftpräsenz (Materiale Textkulturen 2), Berlin, 59-84.

Kuhn-Forte, Brigitte (1997), Die Kirchen innerhalb der Mauern Roms, S. Teodoro bis Ss. Vito, Modeste e Crescenzia. Die Kirchen von Trastevere (Walther Buchowiecki, Handbuch der Kirchen Roms 4), Wien.

Lambert, Chiara (2013), „I documenti epigrafici“, in: Paolo Peduto, Rosa Fiorillo u. Angela Corolla (Hgg.), Salerno. Una sede ducale della Langobardia meridionale (Studi e ricerche de archeologia e storia dell'arte 16), Spoleto, 45-59.

Liess, Reinhard (1985/86), „Der Riss C der Straßburger Münsterfassade. J. J. Arhardts Nürnberger Kopie eines Originalrisses Erwins von Steinbach“, in: Wallraf-Richartz-Jahrbuch 46/47, 75-117.

Liess, Reinhard/ Köpke, Andrea (1989), „Zur ehemaligen Erwin-Inschrift von 1277 an der Westfassade des Straßburger Münsters“, in: Zeitschrift für die Geschichte des Oberrheins 137, N. F. 98, 105-173.

Lomartire, Saverio (1984), „Epigrafia“, in: Lanfranco e Wiligelmo. Il Duomo di Modena (Ausstellungskatalog „Quando le cattedrale erano bianche“), Modena, 374-413.

Mardersteig, Giovanni (1959), „Leon Battista Alberti e la rinascità del carattere lapidario romano nel Quattrocento“, in: Italia medioevale e umanistica 2, 285-307.

Marazzi, Federico (2008), „San Vincenzo al Volturno. L'impianto architettonico fra VIII e XI secolo alla luce dei nuovi scavi della basilica maior“, in: Flavia De Rubeis u. Federico Marazzi (Hgg.), Monasteri in Europa occidentale (secoli VIII-XI). Topografia e strutture, Rom, 323-390.

Marazzi, Federico (2010), „Leggere la storia di San Vincenzo al Volturno attraverso il Chronicon Vulturnense. Segni, disegni, e percorsi di una narrazoni monastica“, in: Massimo Oldoni (Hg.), Chronicon Vulturnense de Monaco Giovanni scritto intorno all'anno 1139, Cerro al Volturno, XXI-XLV.

Marazzi, Federico (2014), San Vincenzo al Volturno. Guida alla città monastica benedettina (Le guide di altri itinerari 4), Cerro al Volturno.

Mitchell, John (1990), „Literacy displayed. The use of inscriptions at the monastery of San Vincenzo al Volturno in the early ninth century“, in: Rosamond McKitterick (Hg.), The uses of literacy in Early Mediaeval Europe, Cambridge u. a., 186-225.

Mitchell, John (1994), „The display of script und uses of painting in Longobard Italy“, in: Testo e immagine nell'Alto Medioevo (Settimane di studio del Centro Italiano di Studi sull'Alto Medioevo 41, 1993), Spoleto, 887-951.

Mitchell, John (1999), „Fragmente einer Monumentalinschrift aus San Vincenzo als Volturno“, in: 799. Kunst und Kultur der Karolingerzeit. Karl der Große und Leo III. in Paderborn, Bd. 2 (Katalog der Ausstellung in Paderborn, 1999), hg. v. Christoph Stiegemann u. Matthias Wemhoff, Mainz, 572f., Nr. VIII.54.

Musmeci, Marco (Hg.) (2003), Templum Mirabile (Atti del Convegno, 2001), Rimini.

Natella, Pasquale (2000), „Palacium et Ecclesiam Instituit. Storia del complesso longobardo di San Pietro a Corte di Salerno“, in: Mariano Greco (Hg.), San Pietro a Corte. Recupero di una memoria nella città di Salerno, Neapel, 87-132.

Nilgen, Ursula (1999), „Fassadenmosaik von Alt-Sankt Peter in Rom“, in: 799. Kunst und Kultur der Karolingerzeit. Karl der Große und Leo III. in Paderborn, Bd. 2 (Katalog der Ausstellung in Paderborn, 1999), hg. v. Christoph Stiegemann u. Matthias Wemhoff, Mainz, 611-613, Nr. IX.3.

Noehles, Karl (1966), „Die Kunst der Cosmaten und die Idee der Renovatio Romae“, in: Günther Fiensch u. Max Imdahl (Hg.), Festschrift Werner Hager, Recklinghausen, 17-37.

Pantoni, Angelo (1962), „Due iscrizioni di San Vincenzo al Volturno e il loro contributo alla storia del cenobio“, in: Samnium, 35, 74-79.

Paulucci, Domenico (1993), Il tempio malatestiano di Rimini (Mirabilia urbis), Rimini. 
Peduto, Paolo (2001), „Paolo Diacono e la capella palatina di Salerno“, in: Paolo Diacono i il Friuli altomedievale (secc. VI-IX) (Atti del XIV Congresso internazionale di studi sull'Alto Medioevo, Cividale, 1999), Spoleto, 655-670; wiederabgedruckt in: Paolo Peduto (Hg.), Materiali per l'archeologia medievale, Salerno 2003, 37-57.

Peroni, Adriano (2008), „L'architetto del primo medioevo. Problemi di identità“, in: Maria Monica Donato (Hg.), L'artista medievale (Annali della Scuola normale superiore di Pisa, ser. IV, Quaderni 16, 2003), Pisa, 27-38.

Piccolomini, Eneas (1582), Commentarii, Rom.

Portoghesi, Paolo (2012), „I riflessi del portico della cattedrale di Civita Castellana nell'architettura italiana del Rinascimento“, in: Luca Creti (Hg.), La cattedrale cosmatesca di Civita Castellana (Atti del convegno internazionale di studi, Civita Castellana, 18-19 settembre 2010), Rom, 243-251.

Réfice, Paola (1993), „Canoni, Tavole dei“, in: Enciclopedia dell'arte medievale 4, Rom, 135-143.

Ricci, Corrado (1924), Il Tempio Malatestiano, Mailand.

Schad, Oseas (1617), Summum Argentoratensium Templum: Das ist die Außführliche u. eigentliche Beschreibung deß viel Künstlichen, sehr Kostbaren, vnd in aller Welt berühmten Münsters zu Straßburg, Straßburg.

Scheins, Martin (1901), „Die karolingische Widmungsinschrift im Aachener Münster“, in: Zeitschrift des Aachener Geschichtsvereins 23, 403-408.

Schoder, R. V. (1979), „Clitumnus“, in: The Princeton encyclopedia of classical sites, 2. Aufl., Princeton, 227.

Semmler, Josef (1989), „Saint Denis. Von der bischöflichen Coemeterialbasilika zur königlichen Benediktinerabtei“, in: Hartmut Atsma (Hg.), La Neustrie. Les pays du Nord de la Loire de 650 à 850, Bd. 2 (Beihefte der Francia 16), Sigmaringen, 75-123.

Tavernor, Robert (1994), „I caratteri albertiani dell'iscrizione del sepolcro Rucellai a Firenze“, in: Leon Battista Alberti (Katalog zur Ausstellung in Mantova, 10. September - 11. Dezember 1994), hg. v. Joseph Rykwert u. Anne Engel, Mailand, 402-407.

Toccaceli, Monica (1996/97), „Abbazie lundo le vie die romei: L'esempio di S. Pietro a Bovara di Trevi“, in: Bollettino storico della Città di Foligno 20/21, 757-771.

Untermann, Matthias (2006), Architektur im frühen Mittelalter, Darmstadt.

Waddell, Gene (2008), Creating the Pantheon. Design, materials, and construction (Bibliotheca archaeologica 42), Rom.

Walter, Joseph (1935), „La topographie de la cathédrale au moyen âge“, in: Bulletin de la sociéte des amis de la cathédrale de Strasbourg, 2. série 3, 37-108.

Zettler, Alfons (2001), Offerenteninschriften auf den frühchristlichen Mosaikfußböden Venetiens und Istriens (Ergänzungsbände zum Reallexikon der germanischen Altertumskunde 26), Berlin.

\section{Bildnachweise}

Abb. 1, 2, 3, 11, 12.1-7, 13, 14.1-8, 15, 16: Matthias Untermann, Heidelberg.

Abb. 4: Monuments de la France classés chronologiquement et considérés sous le rapport des faits historiques et de l'étude des arts, Paris 1816-1836, Bd. 2.

Abb. 5: Mitchell 1994.

Abb. 6, 7: Hodges, Richard / Mitchell, John: The basilica of Abbot Joshua at San Vincenzo al Volturno. Monteroduni 1996, Abb.1.4 und 3.5.

Abb. 8, 17: Berthold Werner, wikimedia commons (CC BY-SA 3.0).

Abb. 9, 28, 29: Miguel Hermoso Cuesta, wikimedia commons (CC BY-SA 4.0). 
Abb. 10: SOLOXSELERNO, wikimedia commons (CC BY-SA 3.0).

Abb. 18, 20: Croberto68, wikimedia commons (CC BY-SA 3.0).

Abb. 19: Paolo Monti, wikimedia commons (CC BY-SA 4.0).

Abb. 21: Roberta Lazzeri, wikimedia commons (CC BY-SA 3.0).

Abb. 22: Quinok, wikimedia commons (gemeinfrei).

Abb. 23: Gianfranco Massetti, wikimedia commons (CC BY-SA 4.0).

Abb. 24: Bulletin de la Societe des Amis de la Cathedrale de Strasbourg 3, 1935, S. 61.

Abb. 25, 26.1-3: Charlotte Lagemann, Heidelberg.

Abb. 27: Staats- und Universitätsbibliothek Göttingen. 